Running Head: Disaggregation

Accepted at Energy Policy

\title{
IS DISAGGREGATION THE HOLY GRAIL OF ENERGY EFFICIENCY? THE CASE OF ELECTRICITY
}

\author{
K. CARRIE ARMEL ${ }^{1 *}$, ABHAY GUPTA $^{2 * *}$, \\ GIREESH SHRIMALI ${ }^{3}$, and ADRIAN ALBERT ${ }^{4}$ \\ ${ }^{1}$ Precourt Energy Efficiency Center, Stanford University \\ E-mail: kcarmel@stanford.edu \\ ${ }^{2}$ Bidgely Inc. \\ E-mail:abhay@bidgely.com \\ ${ }^{3}$ Indian School of Business, and Program on Energy and Sustainable Development at \\ Stanford University \\ E-mail: gireesh_shrimali@isb.edu \\ ${ }^{4}$ Electrical Engineering Department, Stanford University \\ E-mail: adalbert@stanford.edu
}

This document is part of the Precourt Energy Efficiency Center

Technical Paper Series: PTP-2012-05-1

*Address for correspondence: Precourt Energy Efficiency Center, Jerry Yang \& Akiko Yamazaki Environment \& Energy Building, 473 Via Ortega, Room 385, Stanford University, Stanford, CA 94305-4205; 650-380-1965

**Gupta is CEO of Bidgely Inc., a disaggregation company. 


\begin{abstract}
This paper aims to address two timely energy problems. First, significant low-cost energy reductions can be made in the residential and commercial sectors, but these savings have not been achievable to date. Second, billions of dollars are being spent to install smart meters, yet the energy saving and financial benefits of this infrastructure - without careful consideration of the human element - will not reach its full potential. We believe that we can address these problems by strategically marrying them, using disaggregation. Disaggregation refers to a set of statistical approaches for extracting end-use and/or appliance level data from an aggregate, or wholebuilding, energy signal. In this paper, we explain how appliance level data affords numerous benefits, and why using the algorithms in conjunction with smart meters is the most cost-effective and scalable solution for getting this data. We review disaggregation algorithms and their requirements, and evaluate the extent to which smart meters can meet those requirements. Research, technology, and policy recommendations are also outlined.
\end{abstract}

\title{
Keywords
}

Disaggregation, energy efficiency, smart meter 
"If you cannot measure it, you cannot improve it." - Derived from Lord Kelvin

\section{Introduction}

We face several looming energy problems at this junction in history, yet taken together they may offer a unique opportunity for resolution. The first problem relates to the fact that significant low-cost energy reductions can be made in the residential and commercial sectors, but these savings have not been achievable to date. In the United States, the residential and commercial sectors account for much of the demand: buildings in these sectors contribute roughly equally to $40 \%$ of U.S. energy consumed and greenhouse gases emitted (Energy Information Administration, 2008; U.S. Environmental Protection Agency, 2008; Vandenbergh, Barkenbus, \& Gilligan, 2008). It is estimated that about $20 \%$ of this, or $8 \%$ of all U.S. energy use and emissions, could be avoided with efficiency improvements to these buildings (McKinsey \& Company, 2007; Creyts et al., 2007; Gardner and Stern 2008; Laitner, Ehrhardt-Martinez, and McKinney 2009). ${ }^{1}$ Further, this estimate is derived from changes that can be achieved with little or even negative $\operatorname{cost}^{2}$, making savings here particularly attractive (Creyts, 2007). Importantly, experts believe that a major reason why reductions have not yet been achieved in these sectors involves behavioral barriers (IPCC, 2007; American Physical Society, 2008).

The second problem we face is that billions of dollars are being spent to install smart meters yet the energy saving and financial benefits of this infrastructure - without careful consideration of the human element - will not reach its full potential. Business cases justify ratepayer expenditures with reduced labor costs (e.g., meter readers), as well as the avoided generation capacity and lower consumer energy bills that are expected from shifting and reducing energy use (e.g., California Public Utilities Commission, 2006; Faruqui et al., 2011). ${ }^{3}$ It is estimated that the energy shifting and conserving benefits from consumer activities will respectively be about $10 \%$ (Hledik, 2009) and between 1-8\% (EPRI, 2009; Hledik, 2009; Pratt et al., 2010). Estimates to break even on smart grid costs and to attain net positive benefits depend upon consumers achieving these benefits ${ }^{4}$, and it is further hoped that consumer benefits are achieved beyond those estimated (Faruqui et al., 2011; NARUC, 2011). However, some public utility commissions and public interest groups have questioned the benefit (e.g., initial decisions regarding smart meter expenditures in Maryland and Florida; National Association of State Utility Consumer Advocates, 2010). Clearly the ultimate cost or benefit rests to a large degree on facilitating consumer behavior with the meters. Furthermore, the window for realizing the potential of smart meters is closing, if greater hardware capabilities are required. ${ }^{5}$

\footnotetext{
${ }^{1}$ For comparison, $10 \%$ of the total U.S. energy consumption is roughly equivalent to the total yearly energy consumption in Brazil or the UK, or the quantity of fossil fuels that would be saved and greenhouse gas emissions reduced in the U.S. by a 25 -fold increase in wind plus solar power, or a doubling of nuclear power (Energy Information Administration, 2009; Sweeney, 2007).

${ }^{2}$ Assuming a cost of $\$ 50$ per ton of $\mathrm{CO}_{2} \mathrm{e}$.

${ }^{3}$ Business cases are mostly based on those factors (in California, estimates of avoided capacity and reduced energy bills are mostly from demand response). Additional benefits may include: $\mathrm{CO}_{2}$ reductions and other environmental benefits (from reducing energy use, and also load shifting in states where the base load is cleaner than the peaking plants); improved operational efficiency; automatic outage notification, avoidance, and faster recovery; faster transactions and customer service; remote connection and disconnection service; prepayment capability; meter tampering alert; acceleration of electric vehicle adoption; and others (Faruqui et al., 2011; EPRI, 2009; Hledik, 2009; Pratt et al., 2010).

${ }^{4}$ This group estimated that costs per million households are likely to be $\$ 198-272 \mathrm{M}$, while operational savings are likely $\$ 77-208 \mathrm{M}$, and consumer-driven savings are likely $\$ 100-150 \mathrm{M}$. The reader is directed to Faruqui et al. (2011) for specific scenarios from which these figures are derived.

${ }^{5}$ As of June 2011, approximately 20 million smart meters had been deployed in the U.S. It is estimated the number will rise to approximately 65 million meters by 2015 , or about 50 percent of all U.S. households,
} 
How can we address both of these problems simultaneously? Can we leverage smart infrastructure to maximize energy savings and peak shifting in the residential and commercial sectors? We believe that the answer is yes - contingent upon the infrastructure's ability to support disaggregation. Energy disaggregation ${ }^{6}$ refers to a set of statistical approaches for extracting enduse and/or "appliance level"7 data from an aggregate, or whole-building, energy signal. This information affords numerous consumer, R\&D, utility, and policy benefits, as detailed below. Leveraging data from smart meters to perform disaggregation is crucial because other approaches are more costly and labor intensive, and do not provide opportunities for scale.

This paper provides a detailed justification for these ideas. It discusses the benefits of appliance level data, reviews disaggregation algorithms and their requirements, and evaluates whether the technical specifications of smart meters are adequate to support the algorithm requirements. ${ }^{8} \mathrm{We}$ close with a set of specific recommendations for realizing the potential of disaggregation.

\section{Benefits of Appliance-Specific Information}

There are numerous benefits of appliance-specific over whole-home data, summarized in Table 1. These fall into three categories: (1) benefits to the consumer through direct feedback as well as automated personalized recommendations and more, (2) research and development benefits, and (3) utility and policy benefits. The discussion is weighted towards the residential sector due to a bias in existing research, although many of the findings and recommendations should transfer to the commercial sector. Several of these benefits are also discussed in Pratt et al. (2010).

\begin{tabular}{|c|c|c|}
\hline Benefits & Domain & Explanation \\
\hline \multirow{3}{*}{ 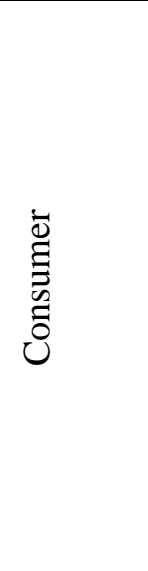 } & \multirow[t]{2}{*}{ Residential Energy Use } & Greater energy reductions from this type of feedback \\
\hline & & $\begin{array}{l}\text { (a) Automated personalized recommendations (through } \\
\text { auto-commissioning, fault detection, elucidating } \\
\text { behavioral patterns, analysis of when and what type of } \\
\text { new appliance to purchase based on current use, etc.), (b) } \\
\text { personalized recommendations allow for personalized } \\
\text { information to reduce barriers to energy efficient actions } \\
\text { (e.g., mapped recommendations on where to purchase } \\
\text { recommended items); enabling of additional/enhanced } \\
\text { behavioral techniques (feedback, competition, } \\
\text { visualizations, markets, incentives, etc.) }\end{array}$ \\
\hline & Commercial Energy Use & $\begin{array}{l}\text { Similar application to residential; large untapped savings } \\
\text { here }\end{array}$ \\
\hline
\end{tabular}

and that by the end of this decade smart meters may be deployed to almost all U.S. households (Faruqui et al., 2011; Institute for Electric Efficiency, 2010). The window for change is even narrower when one considers the contractual and manufacturing timelines that precede installations.

${ }^{6}$ Also referred to as disambiguation, non-invasive load monitoring (NILM), or cognitive metering.

${ }^{7}$ Referred to simply as "appliance level" from here forward. Note this includes anything that draws electricity, such as appliances, electronics, air conditioning and heating, pumps and motors, and water heating loads. This paper focuses on electricity, but similar disaggregation approaches are under development for gas, water, and transportation.

${ }^{8}$ The work presented here grew out of a workshop held at Stanford University in May of 2010. The workshop included a diverse set of stakeholders including disaggregation algorithm developers (both startups and large companies), solid state meter companies, smart meter networking companies, home area network companies, academic researchers, investors, utilities, and government representatives. 


\begin{tabular}{|c|c|c|}
\hline \multirow{2}{*}{ 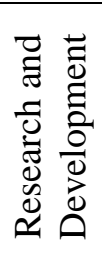 } & Appliance Innovation & $\begin{array}{l}\text { Better data to (a) redesign appliances for energy } \\
\text { efficiency, (b) improved standards, and (c) back up } \\
\text { appliance energy efficiency marketing }\end{array}$ \\
\hline & $\begin{array}{l}\text { Building Research and } \\
\text { Design }\end{array}$ & $\begin{array}{l}\text { Improved building simulation models to increase design } \\
\text { and operational efficiency (commissioning and auto- } \\
\text { commissioning) }\end{array}$ \\
\hline \multirow{4}{*}{ 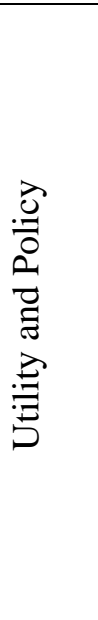 } & $\begin{array}{l}\text { Segmentation for Energy } \\
\text { Efficiency Marketing }\end{array}$ & Strategic, specific, energy efficiency marketing \\
\hline & Program Evaluation & $\begin{array}{l}\text { (a) Improved objectivity, sensitivity, and causal inference } \\
\text { in program evaluation; secondary benefits of (b) } \\
\text { improved program design from improved evaluation } \\
\text { learnings, and (c) diversification of program types, } \\
\text { because these can be quantified, and utilities in many } \\
\text { states are incentivized when program savings can be } \\
\text { quantified }\end{array}$ \\
\hline & $\begin{array}{l}\text { Building and Contractor } \\
\text { Ratings and Incentives }\end{array}$ & $\begin{array}{l}\text { Affords performance based metrics, ratings, and } \\
\text { incentives of buildings which could impact real estate } \\
\text { value, and evaluation of contractor performance }\end{array}$ \\
\hline & $\begin{array}{l}\text { Economic Modeling and } \\
\text { Policy Recommendations }\end{array}$ & $\begin{array}{l}\text { (a) Improved load forecasting; (b) Improved economic } \\
\text { models to better inform policies and funding allocations }\end{array}$ \\
\hline
\end{tabular}

Table 1. A summary of the benefits of appliance specific energy information.

\subsection{Benefits to the Consumer}

Approximately fifty studies have investigated the effects of providing consumers with feedback on their electricity consumption, as illustrated in Figure 1 (for reviews, see Darby 2006; Fischer 2008; Neenan \& Robinson, 2009; Faruqui, Sergici, \& Sharif, 2009; Siddqui, 2008; Ehrhardt-Martinez, Donnelly, \& Laitner, 2010). Several of these suggest that the greatest savings result from appliance-specific feedback (Neenan \& Robinson, 2009; Ehrhardt-Martinez, Donnelly, \& Laitner, 2010), and findings from a recent well-designed simulation study are also consistent (Herter \& Wayland, 2009), although the limited number and size of these studies invites additional work. There are several reasons why appliance specific feedback should facilitate greater reductions than aggregate feedback ${ }^{9}$, and why it offers even greater savings in the future if augmented with additional approaches such as those described below.

\footnotetext{
${ }^{9}$ Feedback and goal-setting are more effective when they are specific and proximate instead of aggregated and distal (for a successful real-world example consider Weight Watchers Points budgeting program; for an academic review see Locke, Saari, Shaw, \& Latham, 1981). Specific feedback improves error management by allowing one to see where actions misalign with goals, and adjust accordingly (Frese and Zapf, 1994). It also provides confirmation about the effectiveness of one's actions, which is reinforcing and increases similar future behavior (Bandura, 1982; Bandura \& Schunk, 1981). Aggregate feedback is limited, given it places the burden of disaggregation on the person (i.e., people typically get useful information from aggregate data by recollecting their activities and mentally decomposing a data graph), and individuals are likely to have difficulty discerning appliance patterns nearly as well as algorithms. It is worth noting that goal-setting has repeatedly enhanced the effectiveness of feedback in a variety of fields, including energy conservation (Bravata et al., 2007; McCalley \& Midden, 2002; Becker, 1978), although it is not yet common in energy feedback programs.
} 


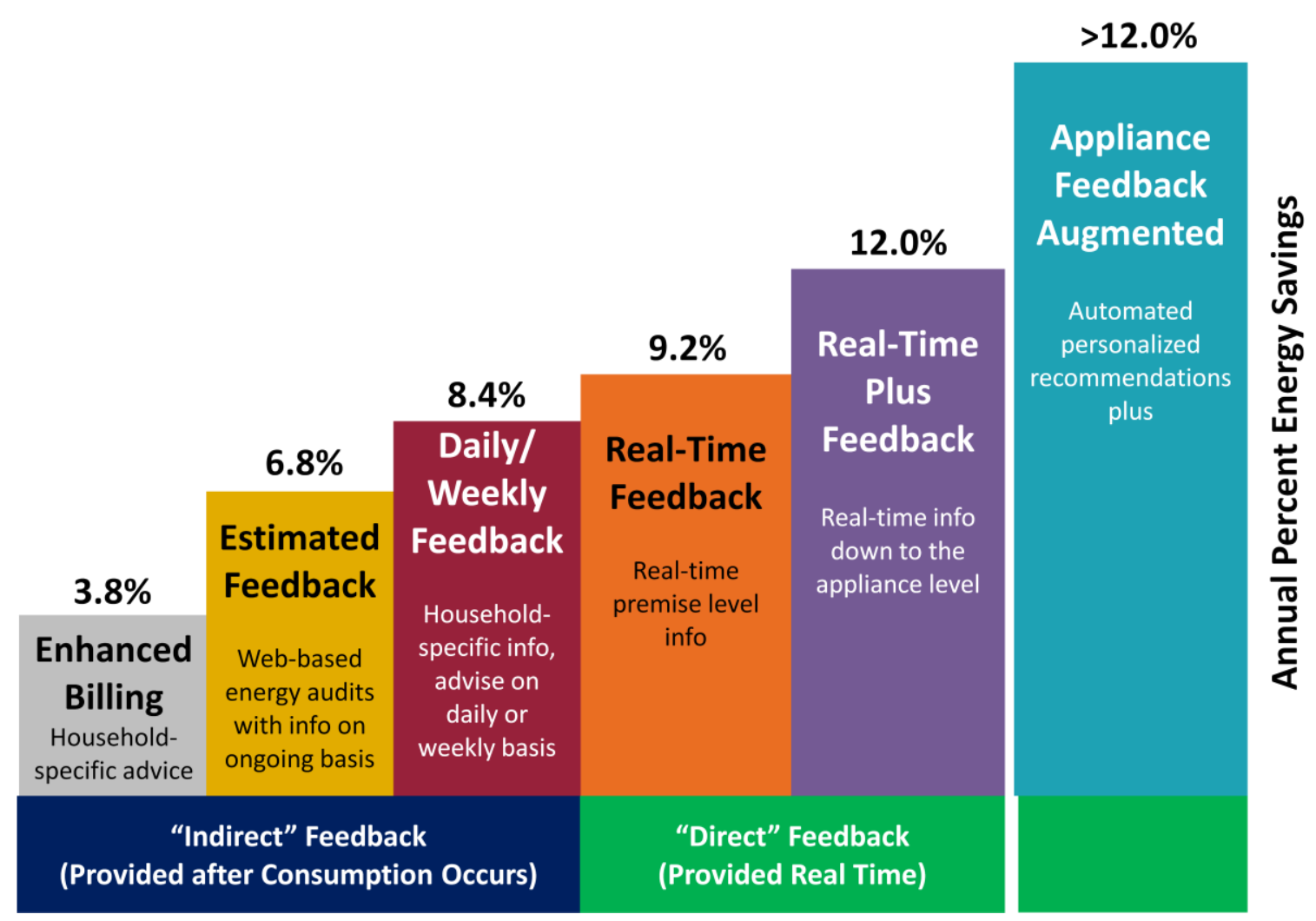

Figure 1. Residential savings due to energy consumption feedback. The five left-most bars are derived from 36 residential electricity studies between 1995-2010 (taken from Ehrhardt-Martinez, Donnelly, \& Laitner, 2010). Many studies were comprised of small samples; the authors estimate that more representative samples and participation rates may result in population savings closer to about half of those indicated. The right-most bar has been added to illustrate that disaggregation and its associated services (diagnostics, recommendations, channeling to programs, new behavioral techniques, targeted marketing, etc.) could be pivotal in achieving greater electricity savings; they could also be used to achieve energy savings in gas use. Achievable energy savings in residential buildings are estimated to be around 20\%, taking population penetration into account (Gardner and Stern 2008; Laitner, Ehrhardt-Martinez, and McKinney 2009). ${ }^{10,11}$

The most important reason why appliance information facilitates greater energy reductions is that it enables automated personalized recommendations - it identifies which specific HVAC systems, appliances, or electronics out of the dozens present could most effectively reduce energy use for a given household or business ${ }^{12,13}$ - and then enables the automated provision of additional

\footnotetext{
${ }^{10}$ See Footnote 1. Also, some case studies and online user communities report achievable savings for individuals above 20\% (e.g., 50\% in Meier, 2010; 75\% in Bailey, 2011; and up to 90\% in the 90 Percent Reduction online group http://groups.yahoo.com/group/90PercentReduction/).

${ }^{11}$ A frequent question about feedback concerns its persistence. Several reviews suggest that savings decline somewhat after the initial few months, and then often remain constant, according to studies that lasted up to three years and used long term feedback (Neenan \& Robinson, 2009; Ehrhardt-Martinez, Donnelly, \& Laitner, 2010).

${ }^{12}$ Some believe this information is intuitive and is limited to obvious appliances like the refrigerator and air conditioner. There are several flaws with this. First, recommendations are likely to vary considerably between households, given that energy consumption varies by 200-300\% in identical housing units, and appliance saturation and use patterns vary significantly across individuals and cultural heritage (Energy
} 
information to overcome barriers and foster action. For example, once actions with the biggest bang for the buck are identified, households or organizations can be matched with appropriate programs, rebates, and contractor options. Recommendations can take into consideration cost, projected energy savings over time, life-cycle energy impact, rebate offers, and local services, and even channel folks into such programs by geographically mapping options and scheduling services. Diagnostics can be performed, for example, to achieve auto-commissioning recommended adjustments to the building operation to improve performance and efficiency - and fault detection - notification if an appliance should be fixed because it is consuming more energy than it should due to a malfunction (Hart, 1992). Notification could be provided if an appliance should be replaced because the lifecycle energy use of a new appliance would be less than the current energy hog. When automated diagnostics are difficult, appliance data could enable remote or virtual diagnostics by experts. Determining how much energy is consumed by different appliances is a first step, and automated recommendation and action systems next steps, to realizing savings. ${ }^{14}$

Once such a system is in place, behavioral approaches - i.e., community, media, and incentive programs - will be much more effective in reducing energy use. For example, engagement channels such as existing real-world community programs and online social networks can be tapped into at low cost to foster widespread use of the recommendation system (Fuller et al., 2010; Sullivan, 2011; Rogers, 1995; Gladwell, 2000). The recommendation system helps people determine what actions they should take, overcome barriers, and connect to action channels (e.g., specific retrofit or appliance replacement programs, contractors, places to purchase the recommended energy efficient items, etc.). Media and incentive programs can continue to engage people once they use the recommendation system, so that they will continue to take energy saving actions. Furthermore, behavioral programs can employ a variety of approaches that all become more effective when quantifying and targeting specific actions, for example: incentives, energy markets, competitions, visualizations, and games and social networking.

Information Administration, 2009; Sudarshan, 2010; for reviews see Lutzenhiser, 1993; Lutzenhiser \& Bender, 2008). Second, reducing energy use on these large appliances may be difficult (not malleable) because they are typically only replaced when they break or during a remodel. Third, limiting recommendations to large appliances or retrofits would miss out on large savings. For example, anecdotal reports from plug monitoring companies, disaggregation developers, and researchers overseeing feedback studies suggest that the largest savings often come from surprising places, such as an extra Tivo, a pool pump, a pottery wheel, or an electric towel or floor warmer, inadvertently left on (personal communication with listed entities; for published work, see Parker et al., 2006; Parker, Hoak, \& Cummings, 2008).

${ }^{13}$ There are numerous actions through which energy savings are achievable, in addition to (1) reducing waste (e.g., above, or a second refrigerator), including (2) the purchase, installation, and proper use of energy efficient technology, (3) the changing of settings and use of control devices (e.g., changing fridge and hot water heater temperature and pool pump cycling rates, and the use of timers and plug monitors), (4) maintenance actions (e.g., cleaning filters), and (5) habits (e.g., turning off the lights and hang drying clothes), and (6) using existing materials creatively e.g. hanging a sheet outside a window to better reduce solar radiation.

${ }^{14}$ Note energy savings from disaggregation can come from identifying opportunities in both machine efficiency (repair and replacement) and operational efficiency (settings, use patterns, etc.). 


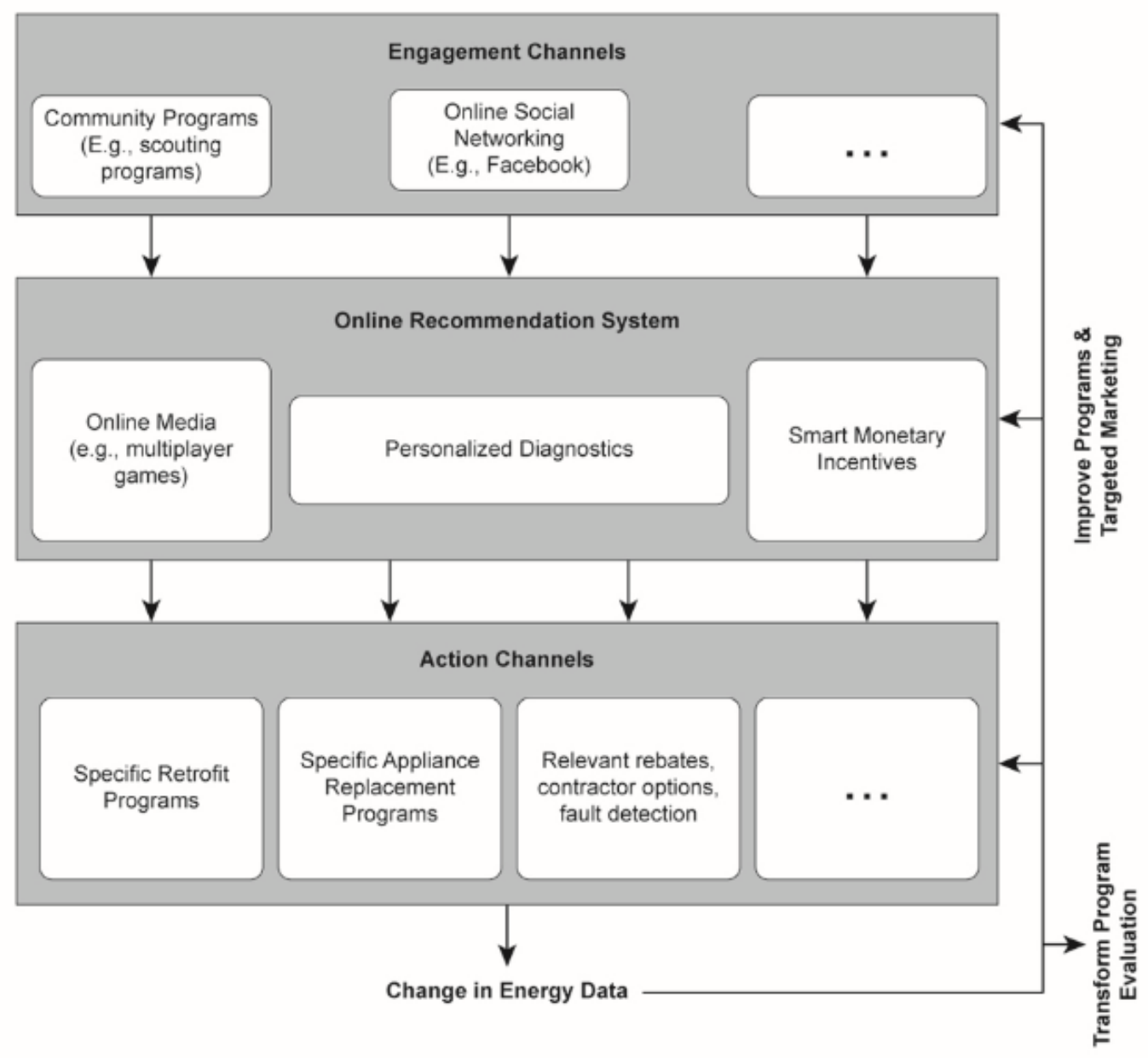

Figure 2. Illustration of an energy behavior change system leveraging appliance level information.

Appliance information is also likely to create demand for control systems, smart appliances, and demand response programs, once people understand where they waste energy. The majority of consumers are unlikely to invest in such devices until they are convinced of the benefit to them personally. Further, the plug controllers and timers needed to perform these functions would be cost prohibitive and too effortful to put on more than a handful of end-uses in the majority of residences, and appliance information would provide guidance on whether and where these would be useful. If consumer demand is present, extensions of these products are likely to emerge. For example, learning algorithms could be developed to detect regularities in consumers' appliance use and preferences to improve efficiency through automated scheduling.

Here we wove together the benefits of appliance specific data into a proposed system capable of realizing the energy saving potential of sensors in the residential sector. Importantly, a similar system could be of significant value in commercial. As a preliminary indication of the size of potential savings, pilot studies with plug monitors in commercial buildings have identified institutional rules and automation that saved a total of between $15-40 \%$ of electricity consumed across the dozens of devices monitored (Mercier \& Moorefield, 2011; Houk, 2010). Disaggregation could be made more tractable in the commercial sector if each segment or even franchise were analyzed separately - for example, all coffee shops or all Starbucks - due to greater homogeneity of devices within that sector. Further, the top-down organizational structure, 
large aggregate savings achievable within a chain or franchise, and greater interest in the bottom line, may make this sector particularly appealing.

\subsection{Research and Development Benefits}

Innovations in energy efficiency would be accelerated with end use specific information. Start-up companies and corporate engineers, academics, and garage dilettantes could all make use of data collected on the actual energy consumption of different appliances and electronics to strategically focus their efforts. Currently, such data is surprisingly sparse and dated. The energy savings due to different appliance modifications could be more easily evaluated, and the best would inform companies about effective revisions to be made to their manufactured goods. As an example, redesign and strategic automated rules developed using such an approach have the potential to produce 15-50\% energy savings on computer and office equipment (Kazandjieva et al., 2010) and servers (Tolia et al., 2008) during idling periods. Companies could also use the information to calculate cost savings from energy efficient appliances to guide investments and marketing strategies (e.g., whether to advertise savings from an appliance upgrade).

End use specific information could improve building efficiency, by clarifying why predicted (i.e., modeled) and actual (i.e., measured) building energy use are discrepant. This discrepancy is large in conventional buildings, but, perhaps more importantly, in "green" buildings, where there are likely to be the best opportunities for building efficiency learnings. Several studies have documented that LEED and other green buildings are only about as efficient as conventional buildings (Scofield, 2002, 2009; Nilsson \& Elmroth, 2005; Kunz, Maile, \& Bazjanac, 2009; Maile, 2010). Much of the discrepancy may be due to a failure in understanding how buildings are being used. Besides differences due to culture, individual routines, occupancy, and appliance saturation (Lutzenhiser, 1993; Lutzenhiser \& Bender, 2008), occupants may use buildings or appliances "incorrectly" for health or comfort reasons (e.g., leaving windows open while heat is on to get fresh air). There is a growing emphasis on measurement and verification to improve energy modeling, and then using these models to improve efficiency (USGBC, 2005; Morrison, Azerbegi, \& Walker, 2008; Turner \& Frankel, 2008). End use specific information is important for three aspects of the building modeling process: (1) to validate the simulation by connecting the parts to the system, (2) to identify opportunities for energy savings, and (3) to help inform interventions in current buildings, and improve designs in new ones, to realize savings.

\subsection{Utility and Policy Benefits}

Energy sensor data, particularly appliance specific data, has the potential to improve energy efficiency marketing - by improving market segmentation, diversifying programs, and transforming program development and evaluation. Market segmentation refers to the process of defining and subdividing a large homogenous market into clearly identifiable segments having similar needs, wants, or demand characteristics. Historical behavior is a strong way of performing market segmentation and targeted messaging - think of book recommendations by Amazon - but most utility marketing is based upon demographic or psychographic characteristics instead. Strategic use of historical energy consumption patterns would allow program designers to target individual consumers as well as whole communities with more specific recommendations and

offers. For example, knowing which consumers or consumer groups (residents, residential communities, businesses, or business sectors) are using energy through air conditioning, pool pumps, or old refrigerators, would allow program designers to target the most appropriate audiences with specific rebates and usage tips. In a similar way, audit and retrofit organizations, and appliance repair companies, could more effectively identify those in need of their services. Such targeted consumer messaging could significantly improve relevance and effectiveness, and reduce the number of people a program must "touch" to achieve a given amount of uptake, 
thereby improving the efficiency of marketing dollars, and ultimately achieving greater energy reductions.

More granular data, particularly appliance data, can also transform program development and evaluation, and diversify the types of programs supported. The data offers a game-changing opportunity because it draws strong links between programs and their energy saving effects that were previously not feasible. This is because energy savings resulting from a given behavior are likely to be swamped in an aggregate energy signal, particularly because consumers are likely to change only a small number of behaviors at any given time. Further, there is strong proof of a program's effectiveness if consumers save energy on the specific behaviors targeted by a program, but not other behaviors. These opportunities significantly improve the objectivity and rigor of program evaluation. Armed with this information, program evaluators can be more successful in their job. Program developers can evaluate, revise, and improve programs more effectively. Programs can be diversified because additional program types can be objectively evaluated, including community and media programs, and when utilities can feasibly evaluate new types of programs, they ${ }^{15}$ have an incentive to diversify their programs and techniques. Improved programs and diversification of programs increase opportunities for energy reductions.

More granular data, including appliance data, could also improve energy models. Enhanced granularity of business and residential energy consumption patterns may increase our ability to predict energy demand annually and seasonally - load forecasting - which is critical for utility company energy purchasing and generation, load switching, contract evaluation, and infrastructure development. More granular data can also improve our understanding of energy consumption patterns, and this can be used to improve the representation of behavior in energy models. Such better representation can make the models more useful when interventions other than pure economic incentives are being considered. This may help policy makers better evaluate utility energy efficiency programs, and allow for better allocation of funds. Most existing models of energy demand are constructed upon a very sparse representation of human behavior and decision making, in part because rich data has not been available to date.

Together, these benefits could provide economic gains, enhance energy security, and help address climate change. Consumers and utilities should be better able to reduce and shift demand. The uptake of energy efficient appliances and electronics may increase because consumers know where energy efficiency improvements need to be made in their homes, or which appliances should be repaired or replaced. The data could lead to performance based metrics, ratings, and incentives in buildings, which could impact their real estate value, and also enable evaluation of contractor performance. Appliance specific data could also spur innovation. Marketing, evaluation, and modeling improvements from more granular data would benefit utilities and other companies selling energy related products and services, program designers and evaluators, and public utility commissions.

\section{How Should We Acquire Appliance-Specific Energy Data? The Business Case for Disaggregation and Smart Meters}

\subsection{Options for Acquiring Appliance-Specific Data}

This section provides an overview of different technologies capable of providing appliance specific data, and their respective pros and cons, particularly those relevant to cost-effectiveness and diffusion potential (see Table 2).

A commonly touted way of obtaining appliance-specific data is to put plug devices on individual appliances, as part of a Home Area Network (HAN). However, this approach has

\footnotetext{
${ }^{15}$ Particularly those in states which provide incentives to utilities for verified savings from energy efficiency programs.
} 
drawbacks. Cost is high for plug monitoring systems, ranging from $\$ 25-50$ per appliance monitor (this could perhaps get to $\$ 10$ at volume) plus a hub or gateway device. Set-up and maintenance are prone to hassle (plugging appliances in and labeling them, redoing this when moving appliances to a new outlet, unless appliance signature identification is used; many prospects for system and node failure). Furthermore, plug level monitoring systems are likely to miss critical energy saving opportunities. Consumers would be unlikely to monitor large appliances due to the difficulty in moving these, as well as the fact that monitors for higher voltage appliances are currently unavailable. Cost and hassle prohibit installation on all plugs, and with a limited number of monitors consumers would be unlikely to monitor "surprise" devices - as mentioned above, much of the energy savings reported by individuals come from devices that they did not anticipate (e.g., potters wheels, x-box, hot tub) (Parker et al., 2006; Parker, Hoak, \& Cummings, 2008; personal communication with energy researchers, plug monitoring companies, and disaggregation developers). Plug monitors also require duplicate hardware and additional energy to operate if a more elegant solution with smart meters can be achieved.

Smart appliances have uncertain impact. These appliances would most likely be limited to white goods, thus missing out on other energy saving opportunities. Also, energy savings would take some time to realize, given that white goods tend to require 12 years for a full market turnover. Further, representatives from two of the largest white good manufacturers told us that their companies planned on introducing smart functionality into high end appliances at a mark-up of approximately $\$ 100$. Only if consumer demand were apparent would they introduce smart features into other lines. Furthermore, the smart features typically emphasize responding to utility demand response events and time of use pricing signals (or consumer convenience); these features would have limited impact if the complementary policies are not in place, creating a chicken and egg problem. These issues raise uncertainty as to the likely impact of smart appliances.

What are the hardware options for enabling disaggregation? Whole-home monitoring devices are commercially available, such as The Energy Detective, BlueLine, and WattVision, which sell for \$150-300 and can forward data of limited resolution (one minute, perhaps up to one second) to disaggregation cloud services (e.g., PlotWatt and Bidgely). Based on extensive experience installing such devices in pilot and study homes, these devices are difficult to get functioning properly and are not compatible with some housing stock (e.g., many apartments). Belkin may be developing an easier to install and higher data frequency device that would perform disaggregation locally, but would likely cost more than these other devices. In addition, these hardware solutions may have some technical and feasibility issues that are not possible to ameliorate $^{16}$, and consume resources to manufacture and energy to operate in addition to that which will be consumed anyhow by smart meters.

In contrast, smart meters offer the lowest cost and lowest installation effort sensor for consumers, and thus show the best potential for high market penetration. This is because there is no apparent cost to the consumer, and installation is performed by utilities. Furthermore, smart meters may be the main option for acquiring gas data.

It is worth noting that one advantage of plug devices over disaggregation is the fact that those devices typically offer control. Thus, we anticipate that the optimal solution will be a combined one of disaggregation leveraging smart meter hardware, augmented with a few strategically placed plug control devices or smart appliances in a subset of homes. Disaggregated appliance information can guide strategic application of control devices, and the two can leverage policies such as time of use pricing and demand response events to encourage efficient timed automation and remote control.

\footnotetext{
${ }^{16}$ E.g., problems with circuit breaker hardware compatibility or location (e.g., outside), connecting to a power supply (or requiring battery replacement several times a year), landlord approval, etc.
} 
The above analysis suggests an important role for disaggregation algorithms, and for smart meters in providing data to these algorithms. Next we assess the feasibility of that solution. Section 4 surveys different types of disaggregation algorithms and their performance, as well as their data requirements. Section 5 assesses whether smart meters can meet these requirements.

\begin{tabular}{|c|c|c|c|c|}
\hline & Sensing Technology & Cost to Consumer & Installation Effort & Adoption Rate \\
\hline \multirow{2}{*}{ 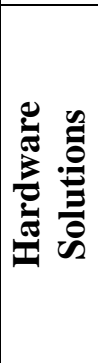 } & $\begin{array}{l}\text { Plug Devices (e.g., } \\
\text { Kill-A-Watt, } \\
\text { EnergyHub, } \\
\text { ThinkEco, Enmetric) }\end{array}$ & $\begin{array}{l}\$ 25-\$ 50 / \text { plug plus } \\
\text { hub cost; hundreds } \\
\text { to thousands per } \\
\text { home }\end{array}$ & $\begin{array}{l}\text { Most plugs - Med } \\
240 \mathrm{~V} \text { plugs - Hard }\end{array}$ & $\begin{array}{l}\text { Low (in existence } \\
\text { for past } 7-8 \text { years) }\end{array}$ \\
\hline & Smart Appliances & $\begin{array}{l}\$ 100+\text { additional } \\
\text { compared to non- } \\
\text { Smart appliances }\end{array}$ & Med & $\begin{array}{l}10-15 \text { years after } \\
\text { introduction for } \\
\text { mass adoption }\end{array}$ \\
\hline \multirow{2}{*}{ 冚 } & $\begin{array}{l}\text { House Level Current } \\
\text { Sensor (e.g., TED, } \\
\text { Blueline) } \\
\text { Monitor of Circuit } \\
\text { Breakers (Powerhouse } \\
\text { Dynamics, Square D) }\end{array}$ & $\$ 150-300+/$ house & Hard & $\begin{array}{l}\text { Low } \\
\text { (high effort }+ \text { cost) }\end{array}$ \\
\hline & Smart Meter & None & None & $\begin{array}{l}\text { Very high \& fast } \\
\text { (installed by } \\
\text { utilities) }\end{array}$ \\
\hline
\end{tabular}

Table 2. Options for obtaining appliance-specific data. Smart meters are the lowest cost and lowest installation effort sensor for consumers, and thus show the best potential for high market penetration. Furthermore, they may be the main option for acquiring gas data for disaggregation.

\subsection{Business Case for Disaggregation}

This section characterizes the cost versus benefit of disaggregation technology (assuming that smart meters are already deployed by the utility and that disaggregation was not considered in the business case ${ }^{17}$ ). We focus on the consumer benefits from residential energy use savings, although other benefits are described in Section 2. As shown in the table below, the cost per $\mathrm{kWh}$ saved can range from $\$ 0.015$ (now) to $\$ 0.005$ (near future). The benefit per $\mathrm{kWh}$ is avoided generation and distribution cost that ranges from $\$ 0.06$ to $\$ 0.10$. Hence, the benefit outweighs the cost by at least a factor of four, and higher in future - making software based disaggregation highly viable for commercialization. For comparison, the average levelized cost of saved energy for electricity efficiency programs is $\$ 0.025$ per $\mathrm{kWh}$ saved, with a range of $\$ 0.016-0.033$ and a median value of $\$ 0.027$ (Friedrich et al., 2009). ${ }^{18}$ These figures are based on technology programs (rather than behavioral programs like Opower) which assume persistence for extended periods; a disaggregation program could target technology replacements such as these, as well as other one time actions (e.g., settings, control, repair) or repeated actions. Because of the program evaluation benefits described above, evaluation of savings could potentially be performed on an ongoing basis, and the monitoring fee adjusted accordingly. Furthermore, whereas programs targeted at

\footnotetext{
${ }^{17}$ Although note that some smart meter business cases rest upon consumer energy saving benefits that have yet to be achieved, as discussed in Section 1, so that disaggregation could help realize these benefits.

${ }^{18}$ The average cost of natural gas programs is $\$ 0.34$ per therm and the median is $\$ 0.32$ (Friedrich et al., 2009).
} 
CFL bulbs or appliances are limited in their potential due to the fact that they can only achieve the savings associated with one end use, disaggregation can target a wide variety of end uses, potentially resulting in much greater total savings.

\begin{tabular}{|l|c|c|c|}
\hline Time -> & Now (2012-13) & \multicolumn{2}{|c|}{ Future (2014+) } \\
\hline $\begin{array}{l}\text { External } \\
\text { Disaggregation Done Where? -> }\end{array}$ & $\begin{array}{c}\text { External } \\
\text { Gateway/Cloud }\end{array}$ & $\begin{array}{c}\text { Smart Meter, } \\
\text { or Broadband } \\
\text { Router/Cloud }\end{array}$ \\
\hline Average monthly household $k W h$ used $^{a}$ & 1,064 & 1,064 & 1,064 \\
\hline $\begin{array}{l}\text { Average reduction with energy } \\
\text { monitor }\end{array}$ & $10 \%$ & $10 \%$ & $10 \%$ \\
\hline Years of life for hardware & 10 & 10 & 10 \\
\hline $\begin{array}{l}\text { Lifetime } k W h \text { saved from home energy } \\
\text { monitor }\end{array}$ & 12,768 & 12,768 & 12,768 \\
\hline $\begin{array}{l}\text { Up front cost of home energy monitor } \\
\text { hardware }\end{array}$ & $\$ 70^{c}$ & $\$ 50^{c}$ & $\$ 10^{d}$ \\
\hline Monthly monitoring fee & $\$ 1.00$ & $\$ 0.50$ & $\$ 0.50$ \\
\hline $\begin{array}{l}\text { Lifetime cost of home energy monitor } \\
(\text { up front cost }+ \text { monthly fee })^{f}\end{array}$ & $\$ 190$ & $\$ 110$ & $\$ 70$ \\
\hline Cost/kWh & $\mathbf{\$ 0 . 0 1 5}$ & $\mathbf{\$ 0 . 0 0 9}$ & $\mathbf{\$ 0 . 0 0 5}$ \\
\hline
\end{tabular}

${ }^{a}$ Source: Energy Information Administration, 2008

${ }^{\mathrm{b}}$ Source: Figure 1 in section 2.1. For a more conservative estimate, a 5\% reduction will double the cost $/ \mathrm{kWh}$ which is still attractive. Upcoming pilots can inform actual effectiveness and persistence.

${ }^{\mathrm{c}}$ Cost for micro-gateway (ZigBee to Ethernet or Wifi bridge with no display) from two vendors in quantities of 10,000 . This cost is unnecessary if smart meters or broadband routers are enhanced instead, as in the final column of the table, and discussed in Section 6.2 and Footnote 30.

${ }^{\mathrm{d}}$ Cost of smart meter enhancements based on Section 6.3.

${ }^{\mathrm{e}}$ Acceptable monthly price per home by disaggregation technology providers when sold in high volumes to a utility.

${ }^{\mathrm{f}}$ The energy consumed by the device itself is small, on the order of $1.2 \mathrm{~W}$, or $105 \mathrm{kWh}$ over its lifetime if run continously.

Table 3. Business case for using disaggregation software with smart meter hardware to obtain appliance specific data.

Regarding the size of the market, as of June 2011 approximately 20 million meters had been deployed in the U.S. with more planned ${ }^{19}$; furthermore, software based disaggregation can also be run with millions of already deployed AMR (Automatic Meter Reading) meters containing Itron technology. This is particularly useful for municipal utilities that are not planning on migrating to smart meters in the near future, and which additionally benefit from the fact that data for billing could be acquired through the same hardware used to enable the disaggregation, thereby reducing costs associated with drive by meter reading. AMR meters produce a reading every minute, and micro-gateways (e.g., from the hardware vendor Digi) can receive this data. The data is then sent to the cloud for disaggregation by algorithms utilizing one minute frequencies, as described in Section 4.1. The cost of these gateways (see Table 3) could come down substantially when read in batch mode (i.e., one gateway reading up to 10 meters in multi-family dwellings, condos, and apartment complexes).

\footnotetext{
${ }^{19}$ See Footnote 5 for more detail.
} 


\section{Disaggregation Algorithms and Their Requirements}

This section surveys different types of disaggregation algorithms and their performance, as well as their data requirements. The survey of algorithm types draws from about 40 academic peer-reviewed empirical studies as well as interviews with smart meter professionals and algorithm developers ${ }^{20}$. For example, some of the companies currently working in this space include High Energy Audits, PlotWatt, Bidgely, Desert Research Institute (DRI), Navetas, General Electric, Intel, and Belkin ${ }^{21}$. An extensive review of the work and a description of the interview questions are included in the appendices. Zeifman and Roth (2011) also recently surveyed this literature; their focus is on comparing algorithmic approaches. Although electricity is the focus of the rest of this paper, the use of disaggregation for other energy-related applications is also promising (i.e., gas, water, and transportation) ${ }^{22}$ (Yamagami, Nakamura, Meier, 1996; Cohn et al., 2010; Patel et al., 2007; Larson et al., 2010; Froehlich et al., 2009a,b).

\subsection{Patterns: Classification of disaggregation algorithms and data requirements}

Disaggregation refers to the extraction of appliance level data from an aggregate, or wholebuilding, energy signal, using statistical approaches. All of the algorithms use the library comparison technique in which an appliance signature database or library is developed by performing physical measurements on appliances. Then new unidentified appliance signals are compared to those signatures in the library to determine the best match.

\footnotetext{
20 These included interviews with six developers, four smart meter companies, and one policy expert AprilMay, 2010. See Appendix C for the core interview script. Non-scripted interviews were also performed with additional professionals when needed for clarification.

${ }^{21}$ Others may include Verdigris Technologies, Detectent, EcoDog, GridSpy, Check-It Monitoring Solutions, and EMME.

${ }^{22}$ Note that the number of appliances or end uses to be disaggregated for gas, water, and transportation is fewer than with electricity, which makes disaggregation easier. However, the frequency of gas and water data may be lower.
} 


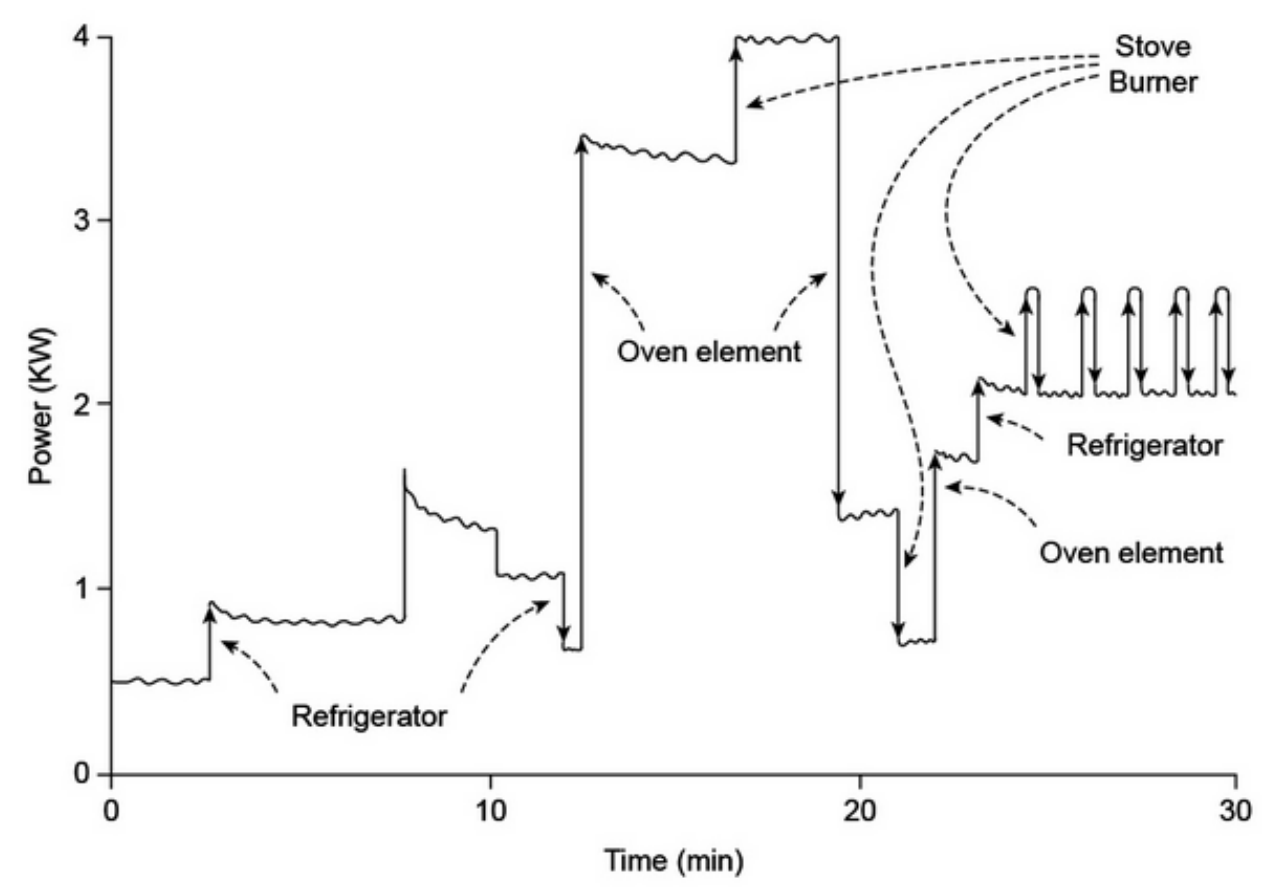

Figure 3. Disaggregation refers to the extraction of appliance level energy use data from an aggregate, or whole-building, energy signal. A set of statistical approaches that extract patterns characteristic of a given appliance are applied to accomplish this. (Figure from Hart, 1992)

The statistical approaches utilize electricity data characteristics including type of power, power level resolution, and frequency. We will next discuss requirements of the algorithms for each of these characteristics. Regarding power, both real and reactive power are useful. The availability of reactive power in addition to real power helps the algorithms running on data sampled at lower frequency in differentiating between loads that have similar real power levels, because they often have different reactive power levels (e.g., a pool pump and a heater).

Power level resolution preferences vary depending on frequency, based on our interviews with disaggregation algorithm developers. Ideally, developers working at the higher frequency ranges $(>1 \mathrm{~Hz})$ and attempting to disaggregate a wider range of appliances want data with power changes of around $0.1 \mathrm{~W}$. This is important in that it allows the algorithms to potentially detect small devices in the homes, especially "small" electronic devices (e.g., DVD players, lower output CFL lights, wireless routers, some printers) which can add up if they are on for a significant portion of the time. Such high resolution requirements become slightly less important at lower frequencies, as the data here is typically not high fidelity enough to identify small loads to begin with. It should be noted that many algorithms will work well with less granular data (e.g., 10W), in that they will still identify the main loads in a house, but simply will have more difficulty identifying smaller loads.

Perhaps the most important pattern to emerge relates to frequency; it is the fact that different ranges of temporal frequency afford different data features, which in turn enable the identification of different numbers and types of appliances (see Table 4). It can be seen that hourly data typically identifies around three end-use categories (i.e., loads that correlate with outdoor temperature, loads that are continuous, and loads that are time-dependent such as pool pumps and outdoor lighting), one minute to one second data allows for identification of $\sim 8$ appliance types, data in the multiple $\mathrm{kHz}$ range identification of 20-40 appliance types, and data in the $\mathrm{MHz}$ range 
identification of potentially close to 100 distinct appliances (e.g., light 1, light 2, etc.). Improved data frequency increases both the number of appliances recognized, and the accuracy with which they are detected, by providing more detailed appliance signatures. It is possible that the frequency-appliance relationship might have shown diminishing returns - e.g., that 10 second data might have identified close to the maximum number of appliances - but that does not appear to be the case (although it might be the case for other measures of accuracy, see footnote 19). 


\begin{tabular}{|c|c|c|c|c|c|c|}
\hline $\begin{array}{l}\text { Data } \\
\text { Frequency } \\
\text { Analyzed }\end{array}$ & $1 \mathrm{hr}-15 \mathrm{~min}$ & $1 \mathrm{~min}-1 \mathrm{~s}(1 \mathrm{~Hz})$ & $1-60 \mathrm{~Hz}$ & $60 \mathrm{~Hz}-2 \mathrm{kHz}$ & $10-40 \mathrm{kHz}$ & $>1 \mathrm{MHz}$ \\
\hline $\begin{array}{l}\text { Data } \\
\text { Appearance }\end{array}$ & 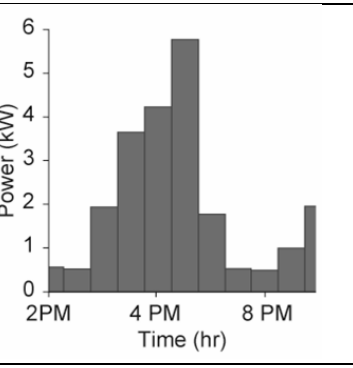 & $\underset{2 \mathrm{pm}}{4}$ & & & 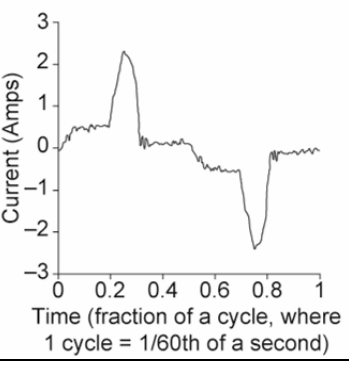 & \begin{tabular}{r|l|l|}
$100 \mathrm{kHz}$ & \\
\end{tabular} \\
\hline $\begin{array}{l}\text { Data } \\
\text { Features } \\
\text { Used by } \\
\text { Algorithms }\end{array}$ & $\begin{array}{l}\text { Visually observable } \\
\text { patterns; duration and } \\
\text { time of appliance use }\end{array}$ & $\begin{array}{l}\text { Steady state steps/ } \\
\text { transitions of power }\end{array}$ & $\begin{array}{l}\text { Steady state } \\
\text { steps/ } \\
\text { transitions of } \\
\text { power }\end{array}$ & $\begin{array}{l}\text { Current and } \\
\text { voltage, } \\
\text { providing } \\
\text { low order } \\
\text { harmonics }\end{array}$ & $\begin{array}{l}\text { Current and voltage, } \\
\text { providing medium } \\
\text { order harmonics to } \\
\text { identify type of } \\
\text { electrical circuitry in } \\
\text { appliance }\end{array}$ & $\begin{array}{l}\text { Current and voltage, } \\
\text { providing very high } \\
\text { order harmonics to } \\
\text { identify both transients } \\
\& \text { the background noise } \\
\text { of appliances }\end{array}$ \\
\hline $\begin{array}{l}\text { Appliances } \\
\text { Identified }\end{array}$ & $\begin{array}{l}\text { Differentiates } \sim 3 \\
\text { general categories: } \\
\text { loads that correlate } \\
\text { with outdoor } \\
\text { temperature, loads } \\
\text { that are continuous, } \\
\text { and loads that are } \\
\text { time-dependent }\end{array}$ & $\begin{array}{l}\text { Top }<10 \text { appliance } \\
\text { types: Refrigerator, } \\
\text { ACs, Heaters, Pool } \\
\text { Pump, Washers, } \\
\text { Dryers etc. }\end{array}$ & $\begin{array}{l}10-20 \\
\text { appliance } \\
\text { types }\end{array}$ & $\begin{array}{l}\text { Not known, } \\
\text { see text for } \\
\text { more details }\end{array}$ & $\begin{array}{l}\text { 20-40 appliance } \\
\text { types: Toasters, } \\
\text { Computers, etc. } \\
\text { along with larger } \\
\text { loads identified at } \\
\text { lower frequencies }\end{array}$ & $\begin{array}{l}\text { 40-100 specific } \\
\text { appliances: e.g., } \\
\text { differentiates between } 2 \\
\text { lights; requires separate } \\
\text { power consumption } \\
\text { data stream }\end{array}$ \\
\hline
\end{tabular}

Table 4. Summary of patterns across existing electricity disaggregation work, derived from approximately 40 studies in Appendix A. Frequencies are grouped into six bins according to developers' preferences, based on hardware and data considerations. Regarding visual appearance, figures in the middle columns appear similar to those on either side. The MHz figure shows a graphical representation of harmonics when the device comes on and off. Regarding data features, power is comprised of current and voltage and when analyzing data at frequencies higher than $60 \mathrm{~Hz}$ practitioners commonly use features derived from the harmonics of these waveforms. Data features at lower frequencies are also available at higher frequencies. Importantly, at different frequencies, different numbers and types of appliances are recognizable. Sampling frequencies above 
$60 \mathrm{~Hz}$ afford the ability to identify types of appliances even if they are always-on ( $15 \%$ of home energy), whereas lower frequencies would have difficulty with this (Zico Kolter, personal communication). Also, algorithms utilizing data of lower frequency require longer durations to get the same number of data points, so that an algorithm using hourly data may require a week to months of data, and one using MHz data can produce results essentially in real time. (1MHz data image from Gupta, Reynolds, \& Patel, 2010) 
Two other findings are worth highlighting. First, higher frequencies (e.g., $60 \mathrm{~Hz}+$ ) afford the ability to identify types of appliances even if they are always-on ( $15 \%$ of home energy), whereas lower frequencies would have difficulty with this (Zico Kolter, personal communication). This is because many devices (even those that are always on) have distinct waveform or harmonic signatures, and sampling frequencies higher than $60 \mathrm{~Hz}$ look at the actual $\mathrm{AC}$ current and voltage waveforms (signatures can be observed even in a single aggregate current waveform). In contrast, looking at real power alone (below $60 \mathrm{~Hz}$ ), loses this information. Second, appliance identification takes longer with lower frequency data, because more time must transpire to collect the same number of data points. Thus, hourly data may require a week to several months of data to tell how much energy was consumed by different end-uses, whereas $\mathrm{MHz}$ sampling can provide this information instantaneously, and the frequencies in between are likely to take from minutes to a few days. This issue may be more or less relevant depending on the use case - e.g., a homeowner with a year's worth of historical data who receives periodic updates, versus a player of a real-time energy video game.

\subsection{Open development questions}

Table 4 also raises questions for future work related to algorithm performance and requirements. First, why has little work been performed in the frequency sampling range from 1 $\mathrm{Hz}$ to $10 \mathrm{kHz}$ ? This may occur for two reasons. To date, the data to develop the algorithms has been collected by academic researchers using laboratory grade sensor hardware, and the cost to sample at $1 \mathrm{~Hz}$ versus $10 \mathrm{kHz}$ is similar, so that there has been no reason to limit the sampling rate below $10 \mathrm{kHz}$. Also, the harmonics available just above $60 \mathrm{~Hz}$ may provide less distinctive signatures of appliances as compared to the signatures obtained at higher frequency $(10 \mathrm{kHz}$ and up). Regardless, $1 \mathrm{~Hz}+$ data may differentiate appliances turned on in quick succession, whereas a rate of 10s (HAN frequency) is not likely to, so that even this modest improvement could be significant. The $1 \mathrm{~Hz}-2 \mathrm{kHz}$ range is of particular interest, given the potential benefit in appliance recognition, and the fact that smart meter hardware may currently be capable of getting this but not $10 \mathrm{kHz}$ data.

Second, there is a large range in the number of appliances recognized in the $10-40 \mathrm{kHz}$ range, and this seems more related to experimental set-ups (e.g., the laboratory selected a set of convenient appliances) rather than the specific frequencies. Clarifying the upper bound on the number of appliances that could be identified in this range would be informative. Note there may be little additional benefit between $15-40 \mathrm{kHz}$ because the noise in that range in real buildings, compared to laboratory set-ups, is likely to obscure any gains in signal detection.

Third, two studies stand out in performing far beyond their class, and suggest a need for innovative thinking in algorithm development. One of these studies (Kolter \& Jaakkola, 2012) was able to identify a number of appliance types from hourly data by utilizing behavioral patterns, such as time of day and duration of use. This suggests that additional types of information could significantly constrain the appliance recognition problem, and opens the door to evaluating the usefulness of property, weather, demographic, and other types of data. Although the accuracy levels of correctly identifying appliances in this study were likely insufficient for commercial use, applying these ideas with higher frequency data (e.g., 1s-1min) seems promising.

The second approach that performed beyond its class utilized a competition strategy among multiple algorithms within the system (Berges et al., 2009, 2010). It matched each new unidentified appliance signature to a library value (i.e., a known appliance signature in a database of such signatures) using several different algorithms, and the one that produced the best match "won". Thus, different appliances might be recognized by different algorithms. Using this 
approach, Berges et al. (2010) improved accuracy around 10\% beyond other algorithms that used a similar frequency.

Thus, 1s-1min data may be sufficient, particularly if appliance recognition is augmented with improved algorithms. However, there may be significant added benefit in the next three higher frequency ranges, warranting additional research. Additional recommendations to facilitate algorithm development include the need for a common reference dataset and definitions of accuracy ${ }^{23}$, testing of the algorithms on commercial meters, and addressing key behavioral research questions ${ }^{24}$.

\section{Smart Meter Hardware Capabilities}

Figure 4 shows a generalized block diagram of a smart meter and its key components. Below we also describe the function of each component, as well as its key data

\footnotetext{
${ }^{23}$ Results reported by different algorithm developers are difficult to compare in greater detail because of their differing data sets and definitions of accuracy. We believe that algorithm development and application would benefit from the creation of a richer, more standardized data set that could be made available publicly (or on an on-request basis). Each algorithm development team has outfitted only a few homes so far, and they include different appliances in their datasets. A standardized dataset would improve the robustness of algorithms across diverse conditions, and facilitate the comparison of different algorithms. Ideally such a data set would capture variability over appliances as well as operating conditions, including a diversity of geographic regions, housing stock, and demographic groups. To be useful for analysis and testing, the dataset should contain both whole-home and ground-truth (i.e., "answer key" data obtained though plug-level monitors) readings at a relatively high sampling rate (e.g., $15 \mathrm{kHz}+$ ). It would be then possible to down sample the high-frequency signal to train and test learning algorithms on data at different frequencies and observe their performance. Collecting such a dataset may require a government funded academic effort, given that developers with the most useful data are reticent to pool it (personal communication). In order to advertise and attract interest from academic and industry researchers, this reference dataset could be the object of a conference or of a competition, in which teams would develop and present innovative algorithms.

Furthermore, common metrics for evaluation should be used. Definitions for accuracy and their formulas should be agreed upon because their diversity currently makes comparing algorithms very difficult. The following definitions have been used: the fraction of correctly recognized events, the fraction of total energy explained, the difference in estimated and true power draw of a given appliance, classification accuracy, fraction of explained energy of each appliance, appliance-wise fraction of load duration, and fraction of "on" intervals missed (Zeifman \& Roth, 2011). Also, the use of the receiver operating characteristic (ROC) curve is likely to be beneficial in showing the tradeoff between sensitivity (probability of Type II error or false negatives) and specificity (probability of Type I error or false positives). Furthermore, other performance characteristics such as delay (e.g., real time appliance identification vs. identification after a week's worth of data) should be articulated for comparison. ${ }^{24}$ It would be beneficial to identify popular use cases and their information requirements, as this has relevance to data handling and consumer display requirements. For example, it would be beneficial to determine which appliances are most important to target with disaggregation. Also, real time processing may be unnecessary if users do not benefit from immediate feedback, and long term storage requirements may be reduced if hourly appliance level information is sufficient (note that the higher frequency data is still required initially to run the algorithms and extract the appliance level data). Perhaps even "snapshots" of energy use patterns are sufficient, so that the algorithms need only to be run, say, on a week of data every few months. To what extent, and in what format, will users answer questions to augment recommendations may also be informative.

Also, in order to develop recommendations of how to reduce energy use based on disaggregated data, it is useful to determine the savings that are achievable from possible recommendations. Disaggregation systems can track energy reduced following a recommendation, and thus readily quantify the impact of many behavioral recommendations that are currently difficult to get (e.g., impact of moving a fridge away from the wall, cleaning its coils, etc.).
} 
processing/transmission constraints. We then explain what would be required to extend capabilities of each component if required. In some cases this would only require firmware upgrade (which is the same as software update); these can be performed remotely and can be appended to routine updates to minimize cost. In other cases extending capabilities might require upgrading the meter hardware. Note there is some ambiguity on constraints, due to variability across meters as well as the fact that exact meter specifications are proprietary and therefore not available to the authors.

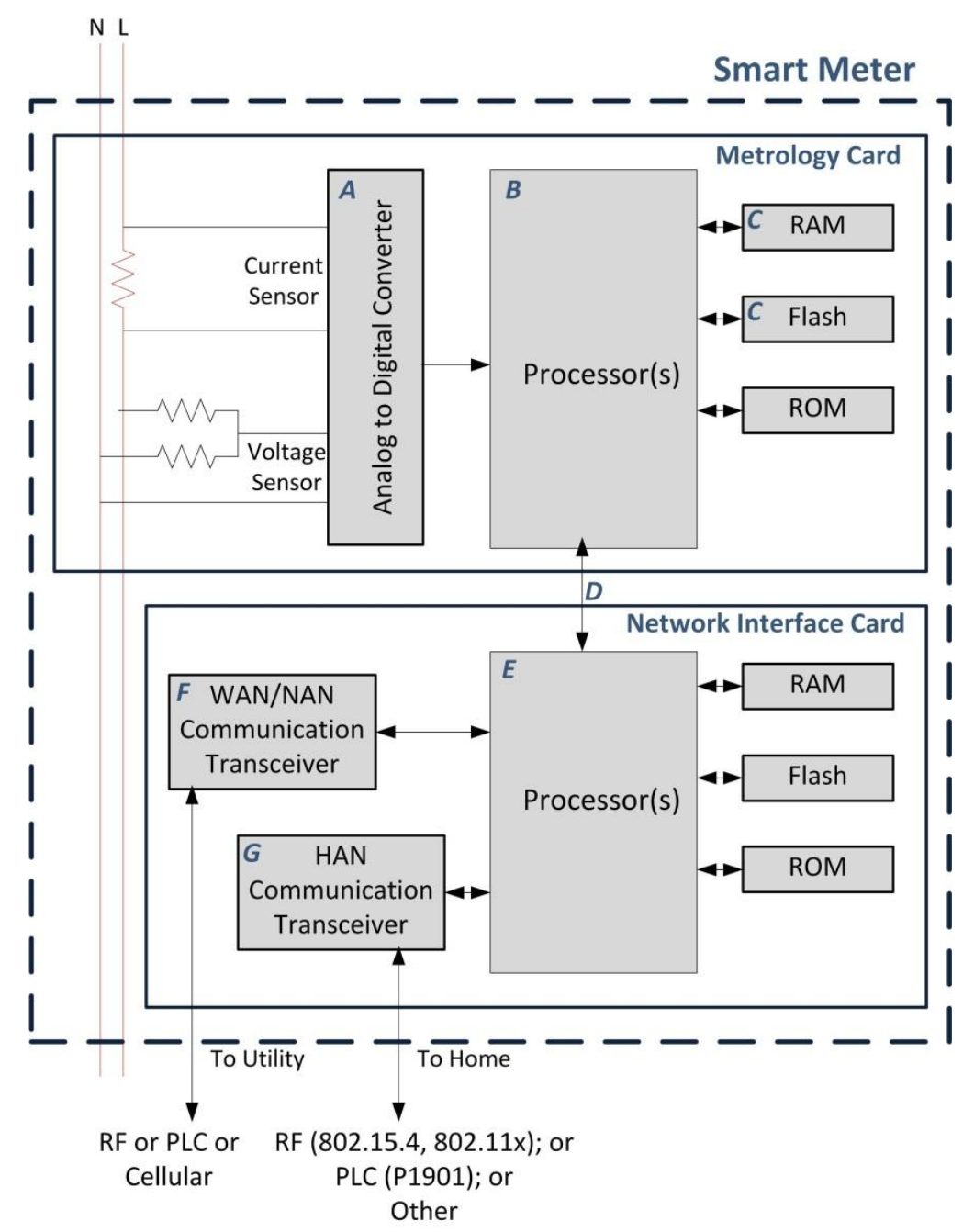

Figure 4. Generalized block diagram of a smart meter. The RAM and Flash memories, although shown off of the processor chip, may be on the processor chip in some cases.

Every manufacturer's products will vary slightly, although the block diagram in Figure 4 is intended to be generic enough to capture the common components and architecture. Smart meters typically have two major components: Metrology and Communications/Network Interface. This distinction is functional - in most cases, they are on separate cards, and to date are typically provided by different vendors, although in some cases they may be integrated on the same card. In most cases, the network interface card is designed to be embedded inside the meter body along with the metrology card so that one product is supplied to the utility in the form of a smart meter. 
Disaggregation 22

\subsection{Metrology Card}

The Metrology card (also referred to simply as the meter) of the smart meter samples the main power line on the load side, measures the instantaneous voltage and current at a certain sampling frequency and uses various calculations to generate the average real power, reactive power, power factor, power quality and several other parameters. It is comprised of:

A. Analog to Digital (A/D) Converter - The A/D converter takes the analog electricity signals for voltage and current which are sampled at predetermined frequencies, converts them to digital values. The power level resolution values that are typically read out of the meter by the communication card are reported on the order of $10 \mathrm{~W}$ to meet the billing requirements. However, data may be capable of being computed to higher resolution internal to the meter, ranging from $\sim 0.5 \mathrm{~W}$ to $\sim 0.0015 \mathrm{~W}$ (depending on the resolution of the $\mathrm{A} / \mathrm{D}$ converter used in the meter ${ }^{25}$ ) and therefore, without any hardware changes, the meter should be able to supply better power level resolution to support energy disaggregation.

Regarding frequency, the meters available in the market offer a range of sampling frequencies. According to the Cisco representative, at the low-medium end of meters, the sampling is around (or below) the fundamental frequency - i.e., $60 \mathrm{~Hz}$. However, at the high end of meters, this can be in the $1-2 \mathrm{kHz}$ range. For example, Itron meters have a sampling rate of $600 \mathrm{~Hz}$ which is equivalent to capturing the $5^{\text {th }}$ harmonic, whereas the Landis $+\mathrm{Gyr}$ Focus AX meter samples at $1724 \mathrm{~Hz}$ which is equivalent to capturing the $14^{\text {th }}$ harmonic. ${ }^{26}$

B. Processor(s) - Out of several processors on the metrology card, the signal processor runs algorithms on the data received from the A/D converter. In particular, it takes the sampled voltage and current values and calculates average power. Regarding type of power, most meters calculate real and reactive power (although they may not send reactive power to the communications card, this could be done with a firmware upgrade). Regarding frequency, interviewees indicated that data leaving the signal processor is likely to be $1-10 \mathrm{~Hz}$, but is likely capable of several kHz. Also, data may currently be smoothed (e.g., averaged over a time window) rather than simply down-sampled, complicating the ability to draw inferences from the data. These issues can be addressed with firmware upgrades to the Flash memory (provided there is enough memory available)

C. Memories (RAM and Flash): Read-Only Access Memory (RAM) is typically used by the processor for intermediate storage during various operations and is not used for storing any results of the signal processing. RAM is a volatile memory and loses its contents if the power to the meter goes down. Data processing constraints from RAM would occur only in the most extreme disaggregation scenarios, and under these scenarios would be upgraded with the Flash memory by sending data to be temporarily stored there. Flash on the other hand is the non-volatile memory (NVM) and holds its contents even if the power to the meter goes down. Since the meter is a cash register for utilities and utilities do not want to lose the information on amount of power consumed by the consumer, most calculations to be sent to utility are stored in Flash memory. When using on-chip memory, the typical size of Flash memory is

\footnotetext{
${ }^{25}$ Using 200A max current and $120 \mathrm{~V}$ power supply (standard for most residential meters in the United States), an 8-bit A/D converter yields about $93 \mathrm{~W}\left(=200 /\left(2^{\wedge} 8\right)\right)$ in power resolution, a 16-bit A/D converter yields $\sim 0.36 \mathrm{~W}$ in power resolution, a 20 -bit $\mathrm{A} / \mathrm{D}$ converter yields $\sim 0.023 \mathrm{~W}$ and a $24 \mathrm{bit} \mathrm{A} / \mathrm{D}$ converter yields $\sim 0.0015 \mathrm{~W}$. In practice, the actual power resolution may be slightly lower due to the fact that most A/Ds have several bits of additional noise, plus a possible mismatch in voltage scales of the A/D and the current transformer.

${ }^{26}$ Recall the fact that, from Nyquist theorem, we need samples at $120 \mathrm{~N} \mathrm{~Hz}$ rate to reconstruct the $\mathrm{N}$-th harmonic. That is, the internal sampling in the $1-2 \mathrm{kHz}$ range can easily provide accurate information up to the $16^{\text {th }}$ harmonic.
} 
between 8 Kbytes and 256Kbytes, and when using off-chip memory, the Flash size is chosen by the meter designer but is typically higher than the on-chip memory. The relevant constraints - the size of Flash memory and the rate of read and write from memory - is usually adequate to support the storage of $>1 \mathrm{kHz}$ sampled data.

\subsection{Network Interface Card}

The second part of the smart meter is the Network Interface Card (NIC). The NIC is the interface to the outside world. It communicates with the metrology part to extract the stored information and communicates with the external world on two interfaces, the Wide Area Network or WAN, and the Home Area Network or HAN. The parts specifications include:

D. Serial Interface: The interface between the metrology section and the network interface card is typically a high speed serial link which is capable of handling data transfer rates of a few $\mathrm{kHz}$.

E. Processor(s): The high end NICs are capable of reading, storing, and reporting data up to 1 $\mathrm{kHz}$, according to a representative of Silver Spring Networks, and potentially higher, depending on the model chosen by a utility. A majority, but not all, communication cards contain processors, which may be sufficiently powerful and have enough memory to perform disaggregation if desirable.

F. Wide Area Network (WAN) Modem/Transceiver (used interchangeably here with Advanced Metering Infrastructure or AMI): The WAN is used by the utilities to extract information out of the smart meter and to send it to the utility central office for further processing. This interface essentially supports automatic meter reading (AMR) for billing and monitoring purposes. The utilities also aim to use this interface for demand side management (DSM), as it would allow them to send signals to the meter and then through the Home Area Network (HAN) to reduce electricity consumption on targeted appliances in the home during high peak periods. WAN can use different kinds of physical interfaces, including power-line communication (e.g., Echelon meters); wireless mesh (e.g., SilverSpring Networks cards); and cellular technology $-3 \mathrm{G}$ or $4 \mathrm{G}$ (e.g., SmartSynch communication cards). The WAN interface typically provides fifteen minute or hourly data. These physical WAN interfaces may have limited capacity to convey information at higher frequencies to the utility central office due to data capacity on the utility servers, the fact that utilities have no obligation or interest in processing higher resolution data, and to a lesser extent bandwidth constraints in the communication networks.

G. Home Area Network (HAN) Modem/Transceiver: HAN refers to a home's local network, rather than the utility's network. It allows the meter to communicate with the home's appliances and/or internet gateway once activated to do so by the utility. HAN can also refer to the network that enables communication of these devices with one another absent the meter, although that is not the focus of this paper. The meter communicates with the in-home devices using the ZigBee PRO standard in most previous and currently planned deployments in United States. ${ }^{27}$ ZigBee PRO is intended to send data up to every 6-7.5 seconds (though some meters based on their design may not send updated data for periods as long as a minute); thus, HAN offers higher frequency data than WAN. We elaborate on HAN frequency below.

\footnotetext{
${ }^{27}$ While this paper references ZigBee PRO as the prevalent HAN communication standard between Smart Meters and in-home devices, several other technologies are under development and standards consideration. We believe most of the recommendations made in this paper will stay relevant if current ZigBee firmware stack is replaced by one of the forthcoming technologies.
} 
Disaggregation 24

\section{Smart Meter Solutions Enabling Disaggregation}

\subsection{Gap Between Algorithm Data Requirements vs. Smart Meter Hardware Capabilities}

Now we look into whether there is a gap between the data requirements of disaggregation algorithms and the current data providing capabilities of smart meters. We look at the three key features of the data described earlier: (a) Type of power; (b) Power level resolution; and (c) Frequency of the data. We specify hardware imposed data constraints and compare these to the algorithm requirements.

\subsubsection{Type of Power}

Reactive power, in addition to real, is useful in disaggregation, as it helps differentiate loads sampled at lower frequencies. Typical meters in the market provide real power, and are generally capable of providing reactive power, in that reactive power is generally available internally to the meter and can be brought out with a firmware upgrade.

\subsubsection{Power Level Resolution}

Developers working at the higher frequency ranges $(>1 \mathrm{~s})$ and attempting to disaggregate a wider range of appliances want power level at $0.1 \mathrm{~W}$ or better resolution. The power level resolution depends on the resolution of the A/D converter and the maximum current supply capability of the meter. Most residential meters in United States provide up to 200A (some go up to $320 \mathrm{~A}$ ) which requires an A/D converter of 20-bit resolution or higher to meet the $0.1 \mathrm{~W}$ data resolution requirement (also see Footnote 25). Developers working at lower frequencies were satisfied with power reported at $10 \mathrm{~W}$ or equivalent magnitude. Current meters are typically constrained to $10 \mathrm{~W}$ to meet the billing requirements, although the meter should be capable of supplying $0.1 \mathrm{~W}$ power level resolution if required.

\subsubsection{Frequency of the Data}

Frequency is the most uncertain in terms of algorithmic requirements and hardware capabilities. Table 5 below shows four different frequency ranges at which the data can be obtained from a smart meter for disaggregation algorithm processing. Regarding the first range, hourly or 15 minutes data delayed by approximately 36 hours may be the only data that is available for the foreseeable future through the Utility WAN. The next two ranges ( $1 \mathrm{~min}-1 \mathrm{~s}$; and $1 \mathrm{~s}-2 \mathrm{kHz}$ ) use the HAN to get the data. The $1 \mathrm{~s}-2 \mathrm{kHz}$ range is where harmonics would begin to become available. Regarding the third range, $1-2 \mathrm{kHz}$ is very close to the internal sampling frequency of the meters and would most certainly need a firmware upgrade to the meter to add more functionality. The fourth frequency range requires changes in meter hardware to support sampling at $10 \mathrm{kHz}+$, which is not currently supported by the A/D converter.

\begin{tabular}{|c|c|c|c|c|c|}
\hline & & $\begin{array}{l}1 \mathrm{hr}- \\
15 \mathrm{~min}\end{array}$ & $1 \min _{1 \mathrm{~s}^{\mathrm{a}}}-$ & $\begin{array}{c}1 \mathrm{~Hz}(1 \mathrm{~s})- \\
2 \mathrm{kHz}\end{array}$ & $\begin{array}{l}10-15 \mathrm{kHz} \\
\text { or higher }\end{array}$ \\
\hline $\mathrm{A}$ & A/D Converter & $\sqrt{ }$ & $\sqrt{ }$ & $\begin{array}{c}\text { X - Needs } \\
\text { firmware } \\
\text { upgrade }\end{array}$ & $\begin{array}{c}\text { X - Needs } \\
\text { hardware upgrade }\end{array}$ \\
\hline B & Metrology Processor & $\sqrt{ }$ & $\sqrt{ }$ & $\sqrt{ }$ & Hardware \\
\hline
\end{tabular}




\begin{tabular}{|c|c|c|c|c|c|}
\hline & & & & & dependent \\
\hline$\overline{\mathrm{C}}$ & Memories & $\sqrt{ }$ & $\sqrt{ }$ & $\sqrt{ }$ & $\begin{array}{c}\text { May support (if } \\
\text { not, needs } \\
\text { hardware upgrade) }\end{array}$ \\
\hline $\bar{D}$ & Serial Interface & $\sqrt{ }$ & $\sqrt{ }$ & $\begin{array}{l}\text { May support (if } \\
\text { not, needs } \\
\text { firmware } \\
\text { upgrade) }\end{array}$ & $\begin{array}{c}\text { X - Needs } \\
\text { hardware upgrade }\end{array}$ \\
\hline $\mathrm{E}$ & $\begin{array}{l}\text { Communications/Network } \\
\text { Interface Processor }\end{array}$ & $\sqrt{ }$ & $\sqrt{ }$ & $\sqrt{ }$ & $\begin{array}{l}\text { Hardware } \\
\text { dependent }\end{array}$ \\
\hline $\mathrm{F}$ & WAN Communication & $\sqrt{ }$ & $\begin{array}{c}\mathrm{X} \text { - Needs } \\
\text { firmware } \\
\text { upgrade }\end{array}$ & $\mathrm{X}$ & $\mathrm{X}$ \\
\hline G & HAN Communication & $\sqrt{ }$ & $\sqrt{ }$ & $\begin{array}{l}\text { X - May be } \\
\text { possible with } \\
\text { compression } \\
\text { (which needs } \\
\text { firmware } \\
\text { upgrade) }\end{array}$ & $\begin{array}{c}\text { X - may be } \\
\text { possible with high } \\
\text { compression; } \\
\text { otherwise } \\
\text { disaggregation } \\
\text { would need to be } \\
\text { done on the meter } \\
\text { (which needs } \\
\text { firmware upgrade) }\end{array}$ \\
\hline
\end{tabular}

${ }^{a}$ These times are approximate. Currently, as described elsewhere in the text, the highest frequency available through the HAN would 6-7.5s.

Table 5. Which data frequency range(s) would be feasible to extract from smart meters, given their constraints, for use in disaggregation algorithms? This table assesses, for each frequency range, whether smart meters could currently supply the data, and, if not, what upgrades would be required to do so. The table was populated with meters from the most popular vendors. Note that either WAN or HAN communication is sufficient; in other words, the WAN constraint is not relevant in the higher frequency ranges as long as HAN communication is viable.

As the frequency requirement increases, we see additional bottlenecks in getting the data out of meter, progressively, due to the WAN, the HAN (ZigBee interface), current meter firmware, the meter hardware (A/D converter) sampling rate, and the network interface card. Regarding the WAN or HAN interfaces, which may impose the biggest bottlenecks, several cases and proposed work-arounds are described below:

1. Sending High Frequency Data $(1 \mathrm{~s}-2 \mathrm{kHz})$ over the HAN. Currently HAN only supports sending one energy value every 6-15 s. The high frequency data can be sent over the HAN by using a combination of following techniques:

a. Compress the data. Several compression techniques are under research that are very promising; for example, a compression ratio of 10,000:1 has been tested (Zico Kolter, in preparation). If successful, this suggests that $\sim 10 \mathrm{kHz}$ data could be sent over the HAN, if used in conjunction with the next technique below.

b. Send packets of higher frequency data. ZigBee provides a connection once every 6-7.5 s and can send up to 80bytes at a time (without the headers). Thus, we could send up to 20 readings every 6-7.5 s - effectively one reading every 0.3-0.375 s-assuming 32-bit values.

c. Replace ZigBee with WiFi or low power WiFi, on next generation meters. This could lessen constraints, given that the typical bandwidth of ZigBee technology is $250 \mathrm{kbps}$ and typical bandwidth of WiFi or low power Wifi is over $1 \mathrm{Mbps}$. 
2. Sending 1 min - $1 \mathrm{~s}$ data over the WAN. Currently smart meters only record and send either 1 hour or at best 15 minute integrated data over the WAN. Given connections are made 1-4 times per day, storing raw data in the meter and sending it through the WAN increases memory and bandwidth requirements. However, sending only event changes can reduce that burden to the point where it could be sent using the existing WAN. ${ }^{28}$ Communication cards with processors should be capable of doing local processing to detect event changes, with a firmware upgrade. Sending $1 \mathrm{kHz}$ sampled data over WAN would likely not be possible with basic compression. ${ }^{29}$

\subsection{Where to Perform Algorithm Processing?}

The previous two sections focused on whether smart meter hardware is capable of supplying adequate data for disaggregation. This section explores where the data can be stored and algorithms run. The options include:

1\&2. In a HAN device or In the Cloud: The first option is to send the data from the meter through the HAN to a consumer display (e.g., in-home display, desktop, laptop, or smartphone), either directly or through the cloud. Either the HAN device or the computers in the cloud would perform disaggregation. ${ }^{30}$

3. On the smart meter: The second option is for data to be stored and processed inside the meter on the network interface card. This is the most scalable option as it does not require any other hardware to be deployed either by the utility or the consumer. The disaggregated results can be sent directly to both the utility and HAN devices - the data size of the disaggregated results is small enough to be sent over both of these interfaces. Since raw sampled data is not sent outside the meter, this option can handle $1 \mathrm{kHz}+$ sampling algorithms, and is only dependent on the meter memory and processing constraints. ${ }^{31}$

4. At the Utility back office: The third option is for the data to be sent to the utility back office via the AMI network and perform the disaggregation on the utility servers, or servers hosted by third parties with data access approved by utilities. We consider this option because it could minimize data duplication at all points in the data chain, so that it

\footnotetext{
${ }^{28}$ For example, a typical household has 2,000 to 4,000 transitions every day (measured from real life data of 10 homes in California by the authors, for transitions greater than 30 watts at 1 second sampling rate); each transition can be stored for 4 bytes each. This translates into sending $\sim 12 \mathrm{Kbytes}=\sim 100 \mathrm{kbits}$ per day. ${ }^{29}$ For example, each $1 \mathrm{kHz}$ sampling transition can be stored for about 4 bytes*1000 $=4 \mathrm{~KB}$ of memory. Hence, 2-4,000 transitions would consume about $8 \mathrm{M}-16 \mathrm{MB}$ of memory. This may be beyond the meter memory and network bandwidth capability.

${ }^{30}$ This option could take several different hardware configurations. That is, the meter could send information through the HAN to a consumer display via: (a) A HAN device capable of receiving ZigBee data from the Smart Meter and communicating with a broadband router (i.e., a WiFi or Ethernet gateway). (b) A broadband router alone, if it is ZigBee enabled. (c) A broadband router alone, if the communications protocol on the meter were WiFi or low power WiFi. Given the availability of WiFi receivers inside most homes already, this option reduces the total cost of ownership and set-up effort, and the increased bandwidth of WiFi also enables transmission of higher frequency data. (d) A $<\$ 100$ USB dongle that is capable of receiving ZigBee; however, this would need to be plugged into a continuously running laptop or desktop that would perform the data storage and disaggregation. (e-g) Any of these configurations could also send data to the cloud for disaggregation (instead of performing disaggregation on the HAN device/router/home computer), as an intermediate step before sending information to the consumer displays.

${ }^{31}$ Indeed, some models of Smart Meters may currently have the capability to perform disaggregation in the communications card, according to one company's representatives, with a firmware upgrade.
} 
has the possibility of being the most cost and energy efficient solution if wellimplemented. However, we consider this option highly unlikely due to the burden and low perceived benefit to utilities.

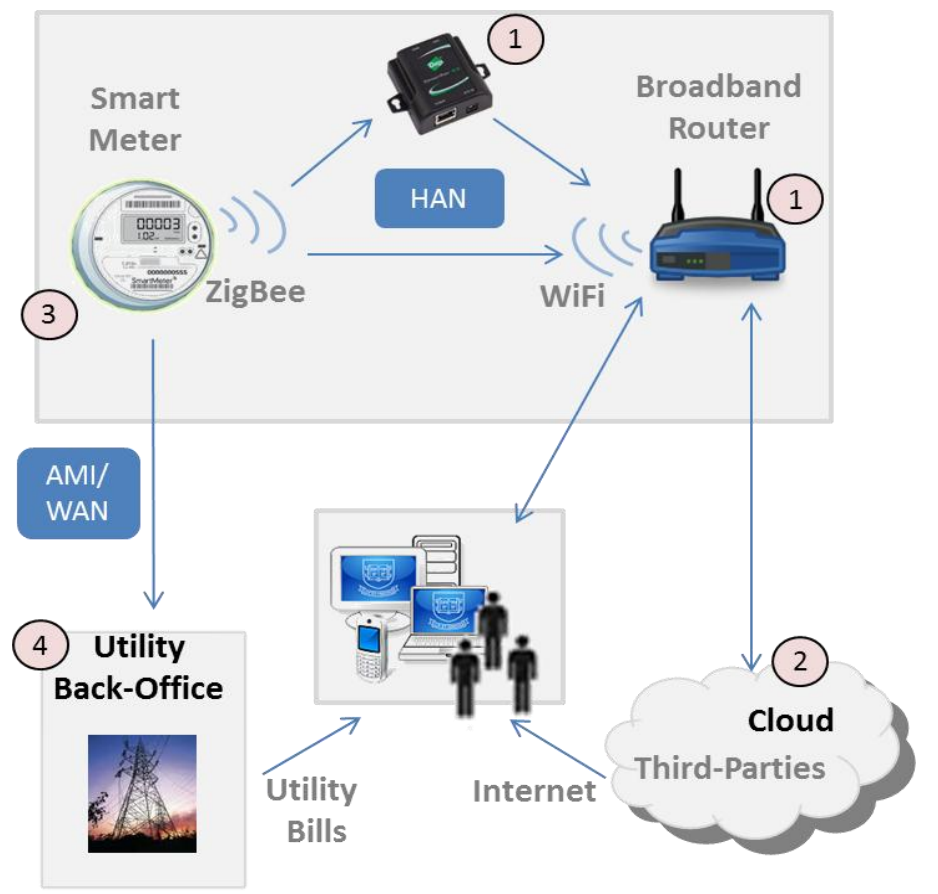

Figure 5. Hardware options for running the algorithms.

\begin{tabular}{|c|c|c|c|c|c|c|c|}
\hline \multicolumn{3}{|c|}{ Disaggregation } & \multicolumn{3}{|c|}{ Requirements for the meter/network } & \multirow[b]{2}{*}{$\begin{array}{l}\text { Data } \\
\text { Frequency } \\
\text { Supported }\end{array}$} & \multirow[b]{2}{*}{ Dependencies } \\
\hline $\begin{array}{c}\text { Reference } \\
\text { to Figure } \\
5 .\end{array}$ & Where? & Comments & $\begin{array}{c}\text { Meter } \\
\text { Memory }\end{array}$ & $\begin{array}{c}\text { Meter } \\
\text { Processing } \\
\text { Power }\end{array}$ & $\begin{array}{l}\text { WAN/ HAN } \\
\text { Bandwidth }\end{array}$ & & \\
\hline $1 \& 2$ & $\begin{array}{l}\text { HAN } \\
\text { gateway } \\
\text { device } \\
\text { or cloud }\end{array}$ & $\begin{array}{l}\text { Currently need } \\
\text { to send data to } \\
\text { HAN gateway } \\
\text { device via } \\
\text { ZigBee }\end{array}$ & Low & Low & $\begin{array}{c}\text { Low to } \\
\text { Moderate, } \\
\text { depending } \\
\text { on } \\
\text { frequency } \\
\text { and } \\
\text { compression } \\
\text { capabilities }\end{array}$ & $\begin{array}{c}1 \mathrm{~Hz}, 1 \\
\mathrm{kHz}^{\mathrm{a}} \text { with } \\
\text { compression }^{2}\end{array}$ & $\begin{array}{c}\text { Utility activation } \\
\text { of HAN; A } \\
\text { ZigBee enabled } \\
\text { HAN gateway } \\
\text { device for } \\
\text { deployed meters, } \\
\text { or low power Wi- } \\
\text { Fi on future } \\
\text { meters }\end{array}$ \\
\hline 3 & Meter & $\begin{array}{c}\text { Send } \\
\text { disaggregated } \\
\text { results back to } \\
\text { Utility or to } \\
\text { HAN gateway } \\
\text { device }\end{array}$ & Low & $\begin{array}{c}\text { High/ } \\
\text { Moderate }\end{array}$ & Low & $\begin{array}{c}1 \mathrm{~Hz}, 1 \\
\mathrm{kHz}+\text { with } \\
\text { compression }\end{array}$ & $\begin{array}{c}\text { Firmware } \\
\text { updates }{ }^{\mathrm{b}} \text { for } \\
\text { deployed meters, } \\
\text { improved } \\
\text { hardware for } \\
\text { future meters }\end{array}$ \\
\hline 4 & $\begin{array}{l}\text { Utility } \\
\text { back } \\
\text { office }\end{array}$ & $\begin{array}{l}\text { Need to send } \\
\text { data back to } \\
\text { Utility back } \\
\text { office via }\end{array}$ & $\begin{array}{l}\text { Moderate } \\
\text { /High }\end{array}$ & Low & Moderate & $\begin{array}{c}1 \mathrm{hr}, 1 \mathrm{~Hz} \\
\text { with } \\
\text { compression }\end{array}$ & Firmware update \\
\hline
\end{tabular}




\section{\begin{tabular}{|c|c|c|c|c|c|}
\hline & WAN & & & & \\
\hline
\end{tabular}}

${ }^{\mathrm{b}}$ Firmware is a part of device software that gets updated periodically for new features or bug fixes. Table 6. Hardware options for running the algorithms and their memory, processing, and bandwidth requirements.

We believe that in the long term, for meters deployed in the future, that Option 3 may be the most efficient and scalable approach, because no hardware is required in the home and bandwidth requirements are minimized. However, in the short term the best option is likely to compress data on the meter, and then use Options 1 or 2 above for performing the disaggregation. This is because for the next couple of years the early algorithms may require frequent updating, which firmware updates are not well-suited for. By compressing the data on the meter and then sending it elsewhere for disaggregation, the processing performed inside the meter does not need to change frequently, but the memory requirements and bandwidth for sending the data outside the meter is reduced. This would entail a firmware upgrade.

In these scenarios, in order to support the actual running of the algorithms, a firmware upgrade is typically sufficient without requiring any hardware changes to the deployed smart meters. It is instructive to note that options 1 and 2 require additional hardware simply because current smart meters predominantly communicate through ZigBee, which cannot communicate directly with the existing internet or other devices commonly found in the home - in other words, such a device is needed for any HAN use. The availability of other HAN protocols that can communicate with the internet, such as WiFi or low-power WiFi, would ameliorate this problem and would open communication between the meter and a variety of internet enabled devices. Note that this does not introduce security problems, but would rather benefit from existing solutions, given the system is already in widespread use and transmits sensitive personal data such as financial and medical information. This option also allows smart meters to be connected to the anticipated "internet of things" for additional consumer applications.

Another way of addressing the sampling, storage, and processing issues discussed here would be to build meters in the future with a serial port and a power supply. Then a large variety of third party devices could be plugged in, directly sampling the power waveform data at the desired frequency; and further storing, processing, and communicating through any networks - for example, the HAN, internet, or cell network. This would enable applications other than disaggregation as well. Some utilities in Europe have chosen meters that have open serial ports for third party hardware that can be installed by the consumers, although this may be difficult to implement in the United States. ${ }^{32}$

\subsection{Cost to Support Disaggregation}

The smart meter changes suggested in the above sections can be classified into two categories - firmware upgrades and hardware modifications. This section describes the cost of making these changes in the smart meters and network infrastructure (either WAN or HAN).

${ }^{32}$ In the United States a redesign is required for the meter case since meters are mostly installed outdoors and any device connecting to the meter needs to be ruggedized just like the meters are. Meter tampering methods would also need to be tightened when deploying such options that allow a user to attach their own device to the meter. Further, a firmware update would likely be required in order to quantify the energy consumption of the third party device in the household's energy bill, rather than being absorbed by utilities as energy consumption of the meter itself as it currently is. Such changes would likely need to be facilitated by policy makers, as incentives are not strongly aligned currently with utilities or meter manufacturers. 
Firmware is a part of device software that gets updated periodically for new features or bug fixes. This would be required when the hardware can perform a function but currently is not. It would include sampling or storing data at higher frequencies, compressing or preprocessing data, sending packets of higher frequency data every 6-7.5 s, expanding the maximum ZigBee packet size, or performing disaggregation on the meter. The typical cost of a firmware upgrade includes: (a) testing the new firmware in the meter or communication card manufacturer's or utility's laboratory, (b) downloading the new firmware over the air into the meter, and (c) supporting the new firmware. When done in conjunction with regular firmware upgrades (typical periodic upgrades done every quarter), the cost for firmware upgrades related to enabling disaggregation can be minimal.

The hardware modifications required vary depending on the sampling frequency used for disaggregation. There are no hardware modifications required to support lower sampling frequency data, but higher frequencies $(1 \mathrm{kHz}+)$ may require one of the following:

a) Increase $\mathrm{A} / \mathrm{D}$ converter sampling rate, and any corresponding processor or memory changes. A rough estimate of the hardware modifications cost for this change may be about $\$ 2-\$ 4$ at cost and about $\$ 10$ at the selling price of the smart meter, according to one of the author's professional experience in smart meter hardware development. Compared to $\$ 200+$ that it takes to purchase and install a smart meter, $\$ 10$ is a modest cost addition to enable a large uptick in energy efficiency.

b) Use WiFi or Low Power WiFi instead of ZigBee ${ }^{33}$ (applicable to where ZigBee might be used as a HAN interface) to support higher data transfer rate from the meter to inside the house, and to ensure more widespread use of the HAN because less installation effort is required by consumers. It is possible that the cost and power consumption for a WiFi chip may be incrementally higher compared to a ZigBee chip, but the incremental cost and power is unlikely to approach that of an extra ZigBee to WiFi gateway required to support HAN functionality. ZigBee enabled routers could address the installation barrier in consumers; however, the broadband router manufacturers will only include ZigBee in mainstream routers if the demand reaches a certain volume which is likely to take several years, and market turnover will take several additional years. The cost and energy consumption comparison of WiFi or Low Power WiFi in the meter versus ZigBee receiver in a router has yet to be determined.

\section{Recommendations and Conclusions}

The work reviewed above suggests that there are compelling reasons to pursue disaggregation, and that it may be possible to leverage existing or future smart meters so that appliance specific information can provide benefits at scale. The following are several specific research and policy recommendations for moving forward.

The following research and development activities are suggested, as well as fiscal support for these:

\footnotetext{
${ }^{33}$ The hardware change required would be to replace IEEE 802.15.4 based radio (used by ZigBee) with IEEE 802.11 (WiFi or low power WiFi) for HAN communication interface in the Smart Meters. If the power consumption of the WiFi chipset is a concern, there are many techniques for reducing wireless energy consumption, such as duty cycling, which is when a device keeps its radio mostly off except when it needs to transmit (Phil Levis, personal communication). Alternatively, there are efforts to develop lower power WiFi chips, for example, by companies such as Gainspan, Marvell, and Atheros (a division of Qualcomm).
} 
1. Improve disaggregation algorithms, in order to improve robustness, accuracy, and number of appliances identified by the algorithms, while reducing frequency, processing, and training requirements. The frequency range of 1 second to $15 \mathrm{kHz}$ is of particular importance, given that insufficient algorithmic work has been performed to date in this range, and this range could be achievable in meters. Develop high-yield data compression algorithms to enable the use of 1 second to $2 \mathrm{kHz}$ data on current meters, and up to $15 \mathrm{kHz}$ data on future meters.

2. Develop a common data set that captures variability over appliances as well as operating conditions. This should increase the rate of development and enable comparison of algorithms, which have been problems to date due to the dearth and variability of data. High resolution data should be recorded when feasible, because it allows for down-sampling and thus for development across a range of frequencies, as well as an assessment of the performance trade-off at different frequencies and resolutions. Such a data set is being created at Stanford, along with a protocol to allow others in geographically diverse regions to contribute. In conjunction with the common dataset, it would be beneficial to: (a) Establish performance metrics, such as common definitions of accuracy to enable the comparison of algorithms. (b) Organize a competition, as has been done previously with algorithm development (e.g., the InfoVis/IEEE Visualization Challenge, http://visweek.org), as this would utilize the dataset and foster algorithm development at universities and beyond.

3. Facilitate testing of compression and disaggregation algorithms on actual smart meters, to evaluate capabilities. Collaboration between universities and industry may prove useful here, for example, in setting up testing facilities.

4. Perform key behavioral research: Identify popular use cases and their information requirements, as this has relevance to data handling and consumer display requirements. For example, it would be beneficial to determine which appliances are most important to target with disaggregation, how often or quickly feedback is required, and whether periodic snapshots of energy use are sufficient in lieu of complete records.

The following steps should be taken to improve data on existing meters. Regarding firmware upgrades, these are similar to software updates, and can be performed remotely and can be appended to routine updates so as to minimize cost.

1. Upgrade firmware to make reactive power available in addition to real power. This allows algorithms to disaggregate more devices.

2. Upgrade firmware to support data compression. Transmitting events/transitions instead of raw load profiles could significantly improve the frequency of data available to HAN devices, as band-with is currently the bottleneck.

Regarding future smart meter hardware and firmware, we recommend the following. These would enable sufficient disaggregation on the meters, without requiring additional hardware that is likely to attain more limited market penetration thereby hindering data access and consumer benefits. New meters should:

1. Be capable of 10-15 $\mathbf{k H z}$ frequency, which would only cost $\$ 5-10$ more (details in Section 6.3), but would likely enable a jump in accuracy and the number of appliances recognized. Improving wattage granularity by enhancing A/D converter resolution (details in Section 6.1.2) would also improve recognition, particularly of smaller electronics, which is of increasing importance given plug loads are the fastest growing segment of electricity use (Ecos, 2006, 2011). 
2. Be capable of supporting disaggregation inside smart meters. This would avoid AMI or HAN network constraints. Firmware loaded onto the meters could be updated for compression and disaggregation either before installation, or through remote firmware upgrades at a later date. Although the algorithms may not be refined enough to make disaggregation on the meters desirable for the next couple of years, ultimately this may be the most cost-effective and scalable solution.

3. Add or replace 802.15.4 based radio (used by ZigBee) with 802.11 (WiFi or low power WiFi) so that meters can communicate directly with the broadband routers, rather than require additional hardware. The additional hardware required by 802.15 .4 interface costs consumers, and is likely to attain limited market penetration thereby hindering data access. The cost of this replacement in the meter would be negligible.

Public utility commissions, utilities, and meter manufacturers should consider the recommendations above when contemplating policy rulings and technology specifications for current and future smart meters. Additional policy recommendations include:

1. Disaggregation developers should contribute use case specifications and requirements to the standards process so that other forthcoming communications technologies are better suited for disaggregation.

2. Institute policies to ensure that utilities enable the HAN communication interface (example ZigBee radios in the meters deployed in CA) soon, at a minimum beginning with pilots. Until such a date few of the benefits of investment into smart meters will be passed on to the consumer. Institute policies to ensure that utilities share de-identified data collected during HAN pilots with research institutes and perhaps companies that are not large enough to participate in the pilots, in order to facilitate algorithm development and other HAN applications.

3. Institute policies, such as rebates, to make HAN gateways (that enable consumers to get real time data from their smart meter) effectively free to consumers. This is similar to \$50-\$150 appliance rebates approved for purchasing an ENERGY STAR appliance on the basis that energy savings during the life of the appliance will be higher than the rebate provided.

4. Institute policies to ensure that utilities select HAN devices during pilots that allow consumers to access or share their data with any third party. This fosters innovation since small businesses can now sell directly to consumers and invest time into developing superior solutions.

5. Federal agencies and PUCs should demand improved transparency about meter specifications, and enable universities to test real meters to establish actual constraints. Currently, some of the relevant meter specifications are proprietary. Large public expenditures are going towards the smart grid, and there is great potential for innovation and consumer benefit, but this is likely to go unrealized without greater transparency.

6. Utilities and regulatory agencies should expediently approve guidelines for addressing privacy issues, if they have not already. Delays prevent individuals from sharing data they own, and limit third parties from helping to realize consumer benefits. Policy is supportive (Chopra, 2011; Chopra, Kundra, \& Weiser, 2011; NARUC, 2011; CPUC, 2011), but implementation has not yet occurred. ${ }^{34}$

\footnotetext{
${ }^{34}$ We believe that privacy should not be a concerning issue for the majority of the public, if addressed appropriately. Individuals have largely become accustomed to the use of personal data, and there is significant precedent for addressing legal and other issues, in numerous domains such as: property records (e.g., Zillow), internet cookies, Google maps, grocery store club cards purchases, health information (Blue
} 
7. Consider slowing the deployment of future smart meters until consumer benefits have been demonstrated, and learnings can be incorporated into future roll outs.

In summary, disaggregation may be the lynchpin to realizing large-scale, cost-effective energy savings in residential and commercial buildings. To date, these " $\$ 20$ on the sidewalk" energy savings have been onerous to collect, but disaggregation offers an opportunity for significant automation. Smart meters, given their widespread roll-outs, and ability to circumvent cost and effort barriers, offer an opportunity for quick, sweeping market penetration of sensing hardware required for disaggregation. There are a number of research, meter, and policy steps needed to realize the application of disaggregation with smart meters, but all are tractable within a relatively short time frame. Further, this work could clear the way for similar energy

disaggregation work on gas, water, and transport. We are optimistic this work will progress, along with its anticipated benefits.

Button initiative), and online finance (transactions, Mint.com). Successful traits of these applications likely include high security, improved convenience, opt-in set-up, and, in the case of online finance, recourse for identity theft. A robust empirical literature on risk perceptions could potentially help improve education and ameliorate concerns (e.g., Slovic, 1987). Additional work extends learnings regarding privacy from other domains to energy sensors such as smart meters and home area networks (Pai et al., 2008; Mulligan \& Perzanowski, 2007; Lisovich \& Wicker, 2008; Subrahmanyam, 2008). 


\section{Acknowledgements}

This work proved to be multifaceted and challenging; we are extremely grateful for the time and expertise provided by so many colleagues. Matthew Nordan, Matt Trevithick, and Erdin Beshimov of Venrock provided critical formative insights, and key assistance with the workshop, networking, and the business case. Zico Kolter provided valuable assistance on the algorithmic discussion. The following contributed valuable information and insights: Chris Villarreal (CPUC), Stacy Angel (EPA), Ryan Hledik (Brattle Group), Martin Fischer (Stanford), James Sweeney (Stanford), Phil Levis (Stanford), Shwetak Patel (U Washington), Jon Froehlich (U Maryland), Alan Meier (LBNL), Ivan O’Neill (while at SCE), Vikki Wood (SMUD), Ed Lu (while at Google), Karen Herter (Herter Associates), Roger Levy (Levy Associates), Ron Hofmann (CaRon Energy Strategies), Kat Donnelly (MIT), Craig Lawrence (SunEdison), Doug Lee, Rebecca Ford, Rafael Friedmann (PG\&E), Martin Kushler (ACEEE), Ed Vine (CIEE), HP Labs, Cisco Systems, Silver Spring Networks, GE, Itron, Landis+Gyr, and others, as well as the companies working on disaggregation mentioned in this paper. Special thanks to Catherine Vogel and Sarah Jo Chadwick for editing assistance. This material is based upon work supported by the Department of Energy ARPA-E under award number DE-AR0000018, the California Energy Commission under award number PIR-10-054, and Precourt Energy Efficiency Center. The views and opinions of authors expressed herein do not necessarily state or reflect those of the United States Government or any agency thereof. 
Disaggregation 34

\section{References}

Akbar, M., Khan, Z. A., 2007. Modified Nonintrusive Appliance Load Monitoring for Nonlinear Devices. IEEE, 2007.

Bandura, A., 1982. Self-efficacy mechanism in human agency. American Psychologist 37, 122147.

Bandura, A., Schunk, D., 1981. Cultivating competence, self-efficacy and intrinsic interest through proximal self-motivation. Journal of Personality and Social Psychology 3(41), 586-598.

Baranski, M., Voss, J., 2003. Non-Intrusive Appliance Load Monitoring Based on an Optical Sensor. EEE Power Tech Conference, Bologna.

Baranski, M., Voss, J., 2004a. Detecting Patterns of Appliances from Total Load Data Using a Dynamic Programming Approach. Proceedings of the Fourth IEEE International Conference on Data Mining (ICDM'04).

Baranski, M., Voss, J., 2004b. Genetic algorithm for pattern detection in NIALM systems. Proceedings of the IEEE International Conference on Systems, Man and Cybernetics, 3462-3468.

Becker, L., 1978, Joint effect of feedback and goal setting on performance: A field study of residential energy conservation. Journal of Applied Psychology 63, 428-433.

Berges, M., Goldman, E., Matthews, S. H., Soibelman, L., 2009. Learning Systems for Electric Consumption of Buildings. Proceedings of the 2009 ASCE International Workshop on Computing in Civil Engineering, Austin, Texas.

Berges, M. E., Goldman, E. H., Matthews, S., and Soibelman, L., 2010. Enhancing Electricity Audits in Residential Buildings with Nonintrusive Load Monitoring. Journal of Industrial Ecology: Special Issue on Environmental Applications of Information and Communication Technologies (ICT), 14(5), 844-858.

Bravata, D. M., Smith-Spangler, C., Sundaram, V., Gienger, A. L., Lin, N., Lewis, R., Stave, C. D., Olkin, I., Sirard, J. R., 2007. Using pedometers to increase physical activity and improve health: a systematic review. JAMA 298 (19), 2296-304.

California Public Utilities Commission, "Final Opinion Authorizing Pacific Gas and Electric Company to Deploy Advanced Metering Infrastructure,' July 20, 2006, No. Decision 05-06-028.

California Public Utilities Commission, "Proposed Decision Adopting Rules to Protect the Privacy and Security of the Electricity Usage Data of the Customers of Pacific Gas and Electric Company, Southern California Edison Electric Company, and San Diego Gas \& Electric Company,"' May 5, 2011, No. Decision 08-12-009.

Chan, W. L., So, A. T. P., Lai, L. L., 2000. Harmonics Load Signature Recognition by Wavelets Transforms. International Conference on Electric Utility Deregulation and Restructuring and Power Technologies, pp. 666-671. 
Chopra, A., 2011. "Modeling a Green Energy Challenge after a Blue Button," The White House Blog. Available at http://www.whitehouse.gov/blog/2011/09/15/modeling-green-energychallenge-after-blue-button.

Chopra, A.; Kundra, V.; and Weiser, P., 2011. A policy framework for the 21st century grid: Enabling our secure energy future. Courtesy of the Executive Office of the President of the United States. Available at http://www.whitehouse.gov/sites/default/files/microsites/ostp/nstcsmart-grid- june2011.pdf

Cohn, G., Gupta, S., Froehlich, J., Larson, E., and Patel, S. N., 2010. GasSense: Appliance-Level, Single-Point Sensing of Gas Activity in the Home. In the Proceedings of Pervasive 2010 (May 17-20, Helsinki, Finland), Springer-Verlag, Heidelberg, 2010, pp. 265-282.

Cox, R., Leeb, S.B., Shaw, S.R., and Norford, L.K. Transient Event Detection for Nonintrusive Load Monitoring and Demand Side Management Using Voltage Distortion. IEEE, 2006, 17511757.

Crabtree, G., 2008. Energy future: Think efficiency. Energy future report, American Physical Society.

Creyts, J., Derkach, A., Nyquist, S., Ostrowski, K., Stephenson, J., 2007. Reducing U.S. greenhouse gas emissions: How much at what cost? U.S. greenhouse gas abatement mapping initiative. McKinsey \& Company Executive Report, McKinsey \& Company.

Darby, S., 2006. The effectiveness of feedback on energy consumption: A review for DEFRA of the literature on metering, billing and direct displays. Technical Report, Environmental Change Institute, University of Oxford, Oxford, England.

Drenker, S., Kader, A., 1999. Nonintrusive monitoring of electric loads. Computer Applications in Power IEEE, 12(4), 47-51.

Ecos. (2006). Energy Use of Plug Load Devices in California Homes: Field Research Report. California Energy Commission, PIER Energy-Related Environmental Research Program. CEC500-04-03. Available at http://www.efficientproducts.org/documents/Plug_Loads_CA_Field_Research_Report_Ecos_200 $\underline{6 . p d f}$

Ecos. (2011). Office Plug Load Field Monitoring Report. California Energy Commission, PIER Energy-Related Environmental Research Program. CEC-500-06-007. Available at http://www.efficientproducts.org/reports/plugload/Revised_Office\%20Plug\%20Load\%20Report PIER_500-06-007_RevApril2011.pdf

Energy Information Administration. (2008). Annual Energy Outlook 2008. Office of Integrated Analysis and Forecasting, U.S. Department of Energy, Washington, DC. DOE/EIA-0383(2008). Available at www.eia.doe.gov/oiaf/aeo/

Electric Power Research Institute (EPRI). 2009. Assessment of Achievable Potential from Energy Efficiency and Demand Response Programs in the U.S.: 2010-2030. EPRI, Palo Alto, CA. 1016987. Available at http://mydocs.epri.com/docs/public/000000000001018363.pdf. 
Ehrhardt-Martinez, K., Donnelly, K. A., Laitner, J. A., 2010. Advanced metering initiatives and residential feedback programs: A meta-review for household electricity-saving opportunities. Tech. Rep. E105, American Council for an Energy-Efficient Economy, Washington, DC.

Farinaccio, L., Zmeureanu, R., 1999. Using a pattern recognition approach to disaggregate the total electricity consumption in a house into the major end-uses. Energy and Buildings, 30(3), 245-259.

Faruqui, A., Fox-Penner, P., Hledik, R., Smart Grid Strategy: Quantifying Benefits, Public Utilities Fortnightly, July 2009.

Faruqui, A., Mitarotonda, D., Wood, L., Cooper, A., Schwartz, J., 2011. The Costs and Benefits of Smart Meters for Residential Customers IEE Whitepaper. The Edison Foundation, Institute for Energy Efficiency White Paper.

Faruqui, A., Sergici, S., Sharif, A., 2009. The impact of informational feed- back on energy consumption - a survey of the experimental evidence. Tech. rep., The Brattle Group, Inc.

Fichman, B., 2009. Energy information administration annual energy review. Report DOE/EIA 0384, U.S. Department of Energy Office of Energy Markets and End Use, Washington, DC.

Fischer, C., 2008. Feedback on household electricity consumption: a tool for saving energy? Energy Efficiency 1(1), 79-104.

Ford, R., 2009. Reducing domestic energy consumption through behaviour modification, Ph.D. thesis, Oxford University.

Frese, M., Zapf, D., 1994. Handbook of industrial and organizational psychology, 2nd ed. Consulting Psychologists Press, Palo Alto, CA, Ch. Action as the core of work psychology: A German approach, pp. 271-340.

Friedrich, K., Eldridge, M., York, D., Witte, P., Kushler, M, 2009. Saving energy costeffectively: A national review of the cost of energy saved through utility-sector energy efficiency programs. Report Number U092, American Council for an Energy-Efficient Economy, Washington, DC.

Froehlich, J., Dillahunt, T., Klasnja, P., Mankoff, J., Consolvo, S., Harrison, B., Landay, J., 2009a. UbiGreen: Investigating a mobile tool for tracking and supporting green transportation habits. Proceedings of CHI 2009, Boston, MA, USA, April 4-9, 2009.

Froehlich, J., Larson, E., Campbell, T., Haggerty, C., Fogarty, J., Patel, S. N., $2009 b$. Hydrosense: Infrastructure-mediated single-point sensing of whole-home water activity. In: Ubicomp 2009 Proceedings of the 11th international conference on Ubiquitous computing, pp. 235-244.

Fuller, M., C. Kunkel, M. Zimring, I. Hoffman, K.L. Soroye, and C. Goldman, 2010. Hood River Conservation Projects, Driving Demand for Home Energy Improvements. LBNL-3960E. 
Gardner, G. T., \& Stern, P. C., 2008. The short-list: The most effective actions US households can take to curb climate change. Environment: Science and Policy for a Sustainable Environment, $50(5), 12-24$.

Gladwell, M., 2000/2002. The Tipping Point: How Little Things Can Make a Big Difference. Little Brown and Company.

Gupta, S., Reynolds, M.S., Patel, S.N., 2010. ElectriSense: Single-Point Sensing Using EMI for Electrical Event Detection and Classification in the Home. In: Ubicomp 2010 Proceedings of the 12th international conference on Ubiquitous computing, pp. 139-148.

Hart, G., 1992. Nonintrusive appliance load monitoring. Proceedings of the IEEE, 80(12), p.1870-1891.

Herter, K., Wayland, S., 2009. Behavioral experimentation with residential energy feedback through simulation gaming. Tech. Rep. CEC-500-2009- XXX, California Energy Commission, PIER Buildings End-Use Energy Efficiency Program.

Hledik R. 2009. “How Green is the Smart Grid?” The Electricity Journal 22(3):29-41.

Hockstadt, L., Cook, B., 2008. Inventory of U.S. greenhouse gas emissions and sinks: 1990-2006. Tech. Rep. 430-R-08-005, U.S. Environmental Protection Agency.

Houck, W., March, 2010. Plugwise. Presentation to Precourt Energy Efficiency Center.

Inagaki, S., Egami, T., Suzuki, T., Nakamura, H., Ito, K., 2011. Nonintrusive Appliance Load Monitoring based on Integer Programming. Electrical Engineering in Japan, 174(2), 18-25.

Institute for Electric Efficiency, 2010. Utility Scale Smart Meter Deployments, Plans, \& Proposals. Available at www.edisonfoundation.net/IEE.

IPCC, 2007. Climate Change 2007: Mitigation. Contribution of Working Group III to the Fourth Assessment Report of the Intergovernmental Panel on Climate Change. Cambridge University Press, Cambridge, United Kingdom and New York, NY, USA.

Kazandjieva, M., Gnawali, O., Heller, B., Levis, P., \& Kozyrakis, C., 2010. Identifying energy waste through dense power sensing and utilization monitoring, Technical Report CSTR 2010-03, Stanford University, Tech. Rep.

Kolter, J. Z. Greedy Approximation to Total Variation Regularization, with Application to Smart Meter Data Compression. In preparation.

Kolter, J. Z., \& Jaakkola, T. Approximate Inference in Additive Factorial HMMs. To appear in the International Conference on Artificial Intelligence and Statistics, 2012.

Kunz, J., Maile, T., Bazjanac, V., 2009. Summary of the energy analysis of the first year of the Stanford Y2E2 building. Technical Report No. 183 version 2, Center for Integrated Facility Engineering (CIFE), Stanford, CA, available online at http://cife.stanford.edu/sites/default/files/TR183.pdf. 
Laitner, J., Ehrhardt-Martinez, K., McKinney, V., 2009. Examining the scale of the behaviour energy efficiency continuum. American Council for an Energy-Efficient Economy, European Council for an Energy Efficient Economy Conference, Cote d'Azur, France, paper ID 1367.

Lam, H. Y., Fung, G. S. K., Lee, W. K., 2007. A Novel Method to Construct Taxonomy of Electrical Appliances Based on Load Signatures. IEEE Transactions on Consumer Electronics, 53(2), 653-660.

Larson, E., Froehlich, J., Campbell, T., Haggerty, C., Fogarty, J., and Patel, S. N., 2010.

Disaggregated Water Sensing from a Single, Pressure-based Sensor: An Extended Analysis of HydroSense using Staged Experiments. The Pervasive and Mobile Computing (PMC) Journal.

Laughman, C., Kwangduk L., Cox, R., Shaw, S., Leeb, S., Norford, L., Armstrong, P., 2003. Power signature analysis. IEEE Power and Energy Magazine, 1(2), 56-63.

Lee, K. D., 2003. Electric load information system based on non-intrusive power monitoring. Ph.D. thesis, MIT.

Lee, K.D., Leeb, S.B., Norford, L.K., Armstrong, P,R., Holloway, J. and Shaw, S.R., 2005, Estimation of Variable-Speed-Drive Power Consumption From Harmonic Content, Energy Conversion, IEEE Transaction on 20. No. 3:566-574.

Lee, W., Fung, G., Lam, H., Chan, F., Lucente, M., 2004. Exploration on load signatures. International Conference on Electrical Engineering (ICEE).

Liang, J., Ng, S. K. K., Kendall, G., Cheng, J. M., 2010. Load Signature Study_Part I: Basic Concept, Structure, and Methodology. IEEE Transactions on Power Delivery, 25(2), 551-560.

Liang, J., Ng, S. K. K., Kendall, G., Cheng, J. W. M., 2010. Load Signature Study_Part II: Disaggregation Framework, Simulation, and Applications. IEEE Transactions on Power Delivery, 25(2), 561-569.

Lisovich, M. A., Wicker, S. B., 2008. Privacy Concerns in Upcoming Residential and Commercial Demand-Response Systems. 2008 Clemson University Power Systems Conference, Clemson University.

Locke, E. A., Saari, L. M., Shaw, K. N., Latham, G. P., 1981. Goal setting and task performance: 1969-1980. Psychological Bulletin 90(I), 125-152.

Lutzenhiser, L., 1993. Social and behavioral aspects of energy use. Annual Review of Energy and the Environment 18(1), 247-89.

Lutzenhiser, L., Bender, S., 2008. The average American unmasked: Social structure and differences in household energy use and carbon emissions. Summer study on energy efficiency in buildings, American Council for an Energy-Efficient Economy summer study, paper 7552.

Maile, T., 2010. Comparing Measured and Simulated Building Energy Performance Data. Ph.D. Thesis, Department of Civil and Environmental Engineering, Stanford University, CA. 
Marceau, M. L., Zmeureanu, R., 2000. Nonintrusive load disaggregation com- puter program to estimate the energy consumption of major end uses for residential buildings. Energy Conversion and Management 41, 1389-1403.

McCalley, L. T., Midden, C. J. H., 2002. Energy conservation through product-integrated feedback: The roles of goal-setting and social orientation. Journal of Economic Psychology 23(5), 589-603.

Mercier, C, \& Moorefield, L., 2011. Commercial office plug load savings and assessment: Final report. Produced by ECOVA and supported through the California Energy Commission's Public Interest Energy Research Program. Available at http://www.efficientproducts.org/reports/plugload/Ecova_Office\%20Plug\%20Load\%20Assessme nt_Final\%20Report\%20Nov\%202011.pdf.

Morrison, L., R. Azerbegi, and A. Walker, 2008. Energy modeling for measurement and verification. Proceedings of the 3rd National Conference of IBPSA-USA, 17-22. Berkeley, CA: International Building Performance Simulation Association (IBPSA).

Mulligan, D. K., Perzanowski, A., 2007. The Magnificence of the Disaster: Reconstructing the Sony BMG Rootkit Incident. Berkeley Technology Law Journal, 22(3), 1157.

Najmeddine, H., Drissi, K. E. K., Pasquier, C., Faure, C., Kerroum, K., Diop, A., Jouannet, T., Michou, M., 2008. State of art on load monitoring methods. In: Proceedings of the 2nd IEEE International Power and Energy Conference (PECon 2008), pp. 1256-1258.

Nakano, Y., Murata, H., Yoshimoto, K., Hidaka, S., Tadokoro, M., Nagasaka, K., 2006. Nonintrusive electric appliances load monitoring system using harmonic pattern recognition performance test results at real households. Proceedings of the IEEE, pp. 477-488.

NARUC Board of Directors' Policy Resolutions passed on Wednesday, July 20, 2011 in Los Angeles. Available at http://summer.narucmeetings.org/2011SummerFinalResolutions.pdf

Neenan, B., Robinson, J., 2009. Residential electricity use feedback: A research synthesis and economic framework. EPRI Technical Update 1016844, Electric Power Research Institute, Palo Alto, CA.

Nilsson, A., Elmroth, A., 2005. The buildings consume more energy than expected. Sustainable City of Tomorrow: B01-Experiences of a Swedish Housing Exposition. Formas, Stockholm, Sweden, 107-118.

Norfold, L. K., Leeb, S. B., 1996. Non-intrusive electrical load monitoring in commercial buildings based on steady-state and transient load-detection algorithms. Energy and Buildings, 24, pp. 51-64.

Pai, S., Meingast, M., Roosta, T., Bermudez, S., Wicker, S. B., Mulligan, D. K., Sastry, S., 2008. Confidentiality in Sensor Networks: Transactional Information. IEEE Security and Privacy, 6(4), 28-35.

Parker, D., Hoak, D., Meier, A., Brown, R., 2006. How much energy are we using? Potential of residential energy demand feedback devices. In: Proceedings of the American Council for an Energy-Efficient Economy Summer Study on Energy Efficiency in Buildings, 1-211: 1-222. 
Parker, D., Hoak, D., Cummings, J., 2008. Pilot evaluation of energy savings from residential energy demand feedback devices. Florida Solar Energy Center, FSEC-CR-1742-08.

Patel, S. N., Robertson, T., Kientz, J. A., Reynolds, M. S., Abowd, G. D., 2007. At the flick of a switch: Detecting and classifying unique electrical events on the residential power line. In: Ubicomp ‘07, LNCS 4717, 271-288.

Powers, J., Margossian, B., Smith, B.,1991. Using a Rule-Based Algorithm to Disaggregate EndUse Load Profiles from Premise-Level Data. IEEE Computer Applications in Power, pp. 42-47.

Pratt RG, PJ Balducci, C Gerkensmeyer, S Katipamula, MCW Kintner-Meyer, TF Sanquist, KP Schneider, and TJ Secrest. 2010. The Smart Grid: An Estimation of the Energy and $\mathrm{CO}_{2}$ Benefits. PNNL-19112 Rev 1, Pacific Northwest National Laboratory, Richland, WA.

Prudenzi, A., 2002. A neuron nets based procedure for identifying domestic appliances patternof-use from energy recordings at meter panel. In Power Engineering Society Winter Meeting.

Rogers, E. M., 1995/2003. Diffusion of innovations. Diffusion of Innovations, 5th Edition. Free Press.

Roos, J., Lane, I., Botha, E., Hancke, G., 1994. Using neural networks for non-intrusive monitoring of industrial electrical loads, Instrumentation and Measurement Technology Conference, $3,1115-1118$.

Scofield, J. H., 2009. Do LEED-certified buildings save energy? Not really... . Energy and Buildings, 41,1386-90.

Scofield, J. H., 2002. Early energy performance for a green academic building. ASHRAE Transactions, 108(2), 1214-1230.

Shaw, S. R., Abler, C. B., Lepard, R. F., Luo, D., Leeb, S. B., Norford, L. K., 1998. Instrumentation for high performance nonintrusive electrical load monitoring, ASME Journal of Solar Energy Engineering, 120(3), 224-230.

Shaw, S. R., Leeb, S. B., Norfold, L. K., Cox, R. W., 2008. Nonintrusive Load Monitoring and Diagnostics in Power Systems. IEEE Transactions on Instrumentation and Measurement, 57, pp. 1445-1454.

Siddiqui, O., 2008. Energy savings and carbon emissions reductions enabled by a smart grid. EPRI Technical Update 1016905, Electric Power Research Institute, Palo Alto, CA.

Slovic, P., 1987. Perception of risk. Science, 236, 280-285.

Srinivasan, D., Ng, W. S., Liew, A. C., 2006. Neural-Network-Based Signature Recognition for Harmonic Source Identification. IEEE Transactions on Power Delivery, 21(1), 398-405.

Subrahmanyam, K., Reich, S., Waechter, N., Espinoza, G., 2008. Online and offline social networks: Use of social networking sites by emerging adults. Journal of Applied Developmental Psychology, 29, pp. 420-433. 
Sudarshan, A., 2010. Deconstructing the 'rosenfeld curve': Why is per capita residential energy consumption in California so low? USAEE-IAEE Working Paper 10 (063), available at SSRN: http://ssrn.com/abstract=1720229 (last accessed December 4th, 2010).

Sullivan, C., 3/18/2011. SMART GRID: Entrepreneurs look to software, IT services for early edge. Greenwire. Available at http://www.eenews.net/Greenwire/2011/03/18/15

Sultanem, F., 1991. Using appliance signatures for monitoring residential loads at meter panel level. IEEE Transaction on Power Delivery 6(4), 1380-1385.

Sweeney, J., 2007. Energy efficiency overview. Snowmass Workshop.

Tolia, N., Wang, Z., Marwah, M., Bash, C., Ranganathan, P., \& Zhu, X. 2008, Delivering energy proportionality with non energy-proportional systems - optimizing the ensemble. In Proceedings of the 1st Workshop on Power Aware Computing and Systems (HotPower '08), San Diego, CA.

Turner, C., Frankel, M., 2008. Energy performance of LEED for new construction buildings. New Buildings Institute.

U.S. Green Building Council, 2005. LEED-NC for new construction: Reference guide, version 2.2. Washington, DC: U.S. Green Building Council.

Vandenbergh, M. P., Barkenbus, J., 2008. Individual carbon emissions: The low-hanging fruit. UCLA Law Review, 55, 1701-58.

Wichakool, A.-T. Avestruz, R., Cox, W, Leeb, S. B., 2009. Modeling and Estimating Current Harmonics of Variable Electronic Loads. IEEE Transactions on Power Electronics, 24(12), 28032811.

Yamagami, S., Nakamura, H., Meier, A., 1996. Non-Intrusive Submetering of Residential Gas Appliances. ACEEE Summer Study on Energy Efficiency in Buildings, 265-273. Washington, D.C.: American Council for an Energy Efficient Economy.

Zeifman, M., Roth, K., 2011. Nonintrusive Appliance Load Monitoring: Review and Outlook. IEEE Transactions on Consumer Electronics, 57(1), 76-84. 


\section{Appendix A. Table of Disaggregation Work}

Algorithms are ordered according to publication date. Several publications are included in the same row if similar, with the study details corresponding to the bolded study. Study details are missing from the table if they were not provided in a publication or by a developer. The different classes of algorithms are described in more detail in Appendix B.

Note that the reported accuracies should not be interpreted as being directly comparable. The accuracy metrics, as well as the appliances tested, data acquisition hardware, environment setting, and amount of data collected, vary substantially from study to study, as detailed below. Regarding accuracy, even when studies use a similar metric, the exact formula often differs. Thus the table should serve mainly as a general compilation of existing approaches, rather than a direct comparison.

\begin{tabular}{|c|c|c|c|c|c|c|c|c|}
\hline Study & Method & Data type(s) & Appliances & $\begin{array}{c}\text { Data acquisition } \\
\text { hardware / } \\
\text { Environmental } \\
\text { setting }\end{array}$ & $\begin{array}{c}\text { Data } \\
\text { Frequency }\end{array}$ & $\begin{array}{c}\text { Amount of } \\
\text { collected data / } \\
\text { Identification } \\
\text { time lag }\end{array}$ & $\begin{array}{l}\text { Accuracy } \\
\text { metric }\end{array}$ & $\begin{array}{l}\text { Reported } \\
\text { accuracy }\end{array}$ \\
\hline Hart (1987-1992) & $\begin{array}{l}\text { steps signatures } \\
\text { database matching }\end{array}$ & $\begin{array}{l}\text { real and } \\
\text { reactive } \\
\text { power }\end{array}$ & $\begin{array}{l}\sim 10 \text { (two-state, } \\
\text { above } 150 \mathrm{~W} \text { ) }\end{array}$ & $\begin{array}{c}\text { custom hardware / } \\
1,3, \& 10 \text { homes }\end{array}$ & $1 \mathrm{~Hz}$ & $\begin{array}{l}\text { several hours / } \\
\text { non real-time }\end{array}$ & $\begin{array}{l}\text { percentage time } \\
\text { on (i.e., } \\
\text { percentage of } \\
\text { energy } \\
\text { explained) of } \\
\text { appliance types }\end{array}$ & $86 \%$ \\
\hline $\begin{array}{l}\text { Sultanem (1991), } \\
\text { Powers et al. (1991), } \\
\text { Prudenzi (2002) }\end{array}$ & $\begin{array}{l}\text { steps signatures } \\
\text { database matching } \\
\text { and classification } \\
\text { using transient } \\
\text { characteristics }\end{array}$ & $\begin{array}{c}\text { current, } \\
\text { voltage, real } \\
\text { and reactive } \\
\text { power }\end{array}$ & not reported & $\begin{array}{c}\text { custom hardware / } \\
\text { laboratory }\end{array}$ & $1.5 \mathrm{kHz}$ & $\begin{array}{c}24 \text { hours / } \\
\text { non real-time }\end{array}$ & $\begin{array}{c}\text { individual } \\
\text { appliance } \\
\text { identification } \\
\text { rate }\end{array}$ & $\begin{array}{l}\sim 95 \% \text { for two- } \\
\text { state appliances }\end{array}$ \\
\hline $\begin{array}{c}\text { Roos et al. (1994), } \\
\text { Srinivasan et al. } \\
\text { (2006) }\end{array}$ & $\begin{array}{c}\text { neural network } \\
\text { classification based } \\
\text { on step changes in } \\
\text { power and current } \\
\text { harmonics }\end{array}$ & $\begin{array}{l}\text { current, } \\
\text { voltage, real, } \\
\text { reactive, and } \\
\text { distortion } \\
\text { power }\end{array}$ & not reported & not reported & not reported & not reported & not reported & not reported \\
\hline
\end{tabular}


Disaggregation 43

\begin{tabular}{|c|c|c|c|c|c|c|c|c|}
\hline $\begin{array}{l}\text { Leeb et al. (1995), } \\
\text { Norfold and Leeb } \\
\text { (1996), Lee et al. } \\
\text { (2005), Wichakol et } \\
\text { al. (2009) }\end{array}$ & $\begin{array}{l}\text { event identification } \\
\text { based on spectral } \\
\text { transients harmonics }\end{array}$ & current & $\begin{array}{l}4 \text { (multi-state, } \\
\text { variable load, } \\
\text { variable speed } \\
\text { drives) }\end{array}$ & $\begin{array}{l}\text { custom hardware / } \\
\text { laboratory setting }\end{array}$ & kHz-range & $\begin{array}{c}\text { real-time } \\
\text { identification }\end{array}$ & $\begin{array}{c}\text { individual } \\
\text { appliance } \\
\text { identification } \\
\text { rate }\end{array}$ & not reported \\
\hline $\begin{array}{c}\text { Drenker and Kader } \\
\text { (1999) }\end{array}$ & $\begin{array}{c}\text { steps signatures } \\
\text { database matching }\end{array}$ & $\begin{array}{l}\text { real and } \\
\text { reactive } \\
\text { power }\end{array}$ & $\begin{array}{c}38 \text { (two-state, } 6 \\
\text { categories) }\end{array}$ & $\begin{array}{l}\text { custom hardware / } \\
\text { laboratory setting }\end{array}$ & not reported & non real-time & $\begin{array}{l}\text { appliance type } \\
\text { identification } \\
\text { rate, percentage } \\
\text { of energy } \\
\text { explained }\end{array}$ & $\begin{array}{c}88 \%-100 \% \\
\text { (identification } \\
\text { rate), } 88 \%-96 \% \\
\text { (percentage of } \\
\text { energy } \\
\text { explained) } \\
\text { (depending on } \\
\text { appliance type) }\end{array}$ \\
\hline $\begin{array}{c}\text { Marceau and } \\
\text { Zmeureanu (2000), } \\
\text { Farinaccio and } \\
\text { Zmeureanu (1999) }\end{array}$ & $\begin{array}{c}\text { steps signatures } \\
\text { database matching }\end{array}$ & current & $\begin{array}{l}\text { several major } \\
\text { appliance types } \\
\text { (water heater, } \\
\text { baseboard heater } \\
\text { and refrigerator) }\end{array}$ & $\begin{array}{l}\text { commercial } \\
\text { hardware / } \\
\text { one home }\end{array}$ & 16 seconds & $\begin{array}{l}\text { seven days each } \\
\text { test and training } \\
\text { / non real-time }\end{array}$ & $\begin{array}{l}\text { percentage of } \\
\text { energy explained } \\
\text { for appliance } \\
\text { types }\end{array}$ & $\begin{array}{l}\text { large variations } \\
(10 \%-95 \%) \\
\text { depending on } \\
\text { appliance type }\end{array}$ \\
\hline $\begin{array}{c}\text { Baranski and Voss } \\
(2004 a), \text { Baranski } \\
\text { and Voss (2003), } \\
\text { Baranski and Voss } \\
\text { (2004b) }\end{array}$ & $\begin{array}{l}\text { finite state appliance } \\
\text { space exploration } \\
\text { through a genetic } \\
\text { algorithm and } \\
\text { clustering }\end{array}$ & not reported & not reported & $\begin{array}{l}\text { electricity meter / } \\
\text { optical sensor }\end{array}$ & not reported & not reported & not reported & not reported \\
\hline $\begin{array}{c}\text { Leeb et al (2006), } \\
\text { Chan et al. (2000), } \\
\text { Akbar and Kahn } \\
(2007), \text { Shaw et al. } \\
(2008)\end{array}$ & $\begin{array}{l}\text { event identification } \\
\text { based on spectral } \\
\text { transients }\end{array}$ & voltage & $\begin{array}{c}\sim 5 \text { (two- and } \\
\text { multi-state, fixed } \\
\text { and variable load) }\end{array}$ & $\begin{array}{c}\text { custom hardware / } \\
\text { laboratory }\end{array}$ & $\mathrm{kHz}$ range & $\begin{array}{c}\text { real-time } \\
\text { identification }\end{array}$ & $\begin{array}{c}\text { individual } \\
\text { appliance } \\
\text { identification } \\
\text { rate }\end{array}$ & not reported \\
\hline Patel et al. (2007) & $\begin{array}{c}\text { machine learning } \\
\text { classification based } \\
\text { on on/off transient } \\
\text { noise }\end{array}$ & $\begin{array}{l}\text { current, } \\
\text { voltage }\end{array}$ & $\begin{array}{l}\sim 20 \text { appliance } \\
\text { types, } \sim 40 \\
\text { appliances per } \\
\text { home } \\
\text { (fixed/variable } \\
\text { load, two- and } \\
\text { multi-state) }\end{array}$ & $\begin{array}{c}\text { custom hardware / } \\
6 \text { homes }\end{array}$ & $\begin{array}{l}100 \mathrm{~Hz}-100 \\
\mathrm{kHz} \text { range } \\
\text { and } 50 \mathrm{kHz}- \\
100 \mathrm{MHz} \\
\text { range }\end{array}$ & $\begin{array}{l}\sim 150-350 \text { events } \\
\text { (train), } \sim 80-100 \\
\text { events (test) / } \\
\text { real-time appliance } \\
\text { identification }\end{array}$ & $\begin{array}{c}\text { individual } \\
\text { appliance } \\
\text { identification } \\
\text { rate }\end{array}$ & $85 \%-95 \%$ \\
\hline
\end{tabular}


Disaggregation 44

\begin{tabular}{|c|c|c|c|c|c|c|c|c|}
\hline $\begin{array}{l}\text { Lam et al. (2007), } \\
\text { Lee et al. (2004) }\end{array}$ & $\begin{array}{l}\text { hierarchical } \\
\text { classification based } \\
\text { on current-voltage } \\
\text { trajectory features }\end{array}$ & $\begin{array}{l}\text { current, } \\
\text { voltage }\end{array}$ & $\begin{array}{l}8 \text { main appliance } \\
\text { types (by physical } \\
\text { characteristics) }\end{array}$ & custom hardware & not reported & not reported & not applicable & not applicable \\
\hline Ford (2009) & $\begin{array}{l}\text { Bayesian-based } \\
\text { membership model } \\
\text { for appliances based } \\
\text { on harmonic and } \\
\text { transient signatures }\end{array}$ & $\begin{array}{l}\text { power, } \\
\text { voltage }\end{array}$ & $\begin{array}{c}4 \text { appliances types } \\
\text { (two- and multi- } \\
\text { state) }\end{array}$ & $\begin{array}{l}\text { custom hardware / } \\
\text { laboratory setting }\end{array}$ & $\sim 15 \mathrm{kHz}$ & $\begin{array}{c}\text { several minutes per } \\
\text { test / } \\
\text { non real-time } \\
\text { identification }\end{array}$ & $\begin{array}{c}\text { individual } \\
\text { appliance } \\
\text { identification } \\
\text { rate }\end{array}$ & $>99 \%$ \\
\hline Berges et al. (2009) & $\begin{array}{c}\text { machine learning } \\
\text { classification based } \\
\text { on appliance } \\
\text { signatures }\end{array}$ & $\begin{array}{l}\text { current, } \\
\text { voltage }\end{array}$ & $\begin{array}{l}8 \text { appliances } \\
\text { (two- and multi- } \\
\text { state) }\end{array}$ & custom hardware & $100 \mathrm{kHz}$ & $\begin{array}{l}\sim 450 \text { events (train), } \\
45 \text { events (test) }\end{array}$ & $\begin{array}{c}\text { individual } \\
\text { appliance } \\
\text { identification } \\
\text { rate }\end{array}$ & $79 \%$ \\
\hline Kolter et al. (2010) & $\begin{array}{l}\text { machine learning of } \\
\text { appliance usage } \\
\text { pattern using } \\
\text { discriminative sparse } \\
\text { coding }\end{array}$ & $\begin{array}{c}\text { energy } \\
\text { consumption }\end{array}$ & $\begin{array}{l}\sim 10 \text { appliance } \\
\text { types }(\sim 1300 \\
\text { appliances })\end{array}$ & $\begin{array}{l}\text { commercial } \\
\text { individual plug } \\
\text { monitors / } \\
\sim 138 \text { homes } \\
\text { (Netherlands) }\end{array}$ & 1 hour & $\begin{array}{l}\sim 200-700 \text { days } \\
\text { parsed weekly / } \\
\text { non real-time } \\
\text { identification }\end{array}$ & $\begin{array}{l}\text { percentage of } \\
\text { energy explained } \\
\text { for appliance } \\
\text { types }\end{array}$ & $55 \%$ \\
\hline Berges et al. (2010) & $\begin{array}{l}\text { machine learning } \\
\text { classification based } \\
\text { on appliance } \\
\text { signatures }\end{array}$ & $\begin{array}{l}\text { power, } \\
\text { voltage }\end{array}$ & 17 appliances & custom hardware & $10 \mathrm{kHz}$ & $\begin{array}{l}5.5 \text { days / non real- } \\
\text { time identification }\end{array}$ & $\begin{array}{l}\text { percentage of } \\
\text { energy explained }\end{array}$ & $86 \%$ \\
\hline Gupta et al. (2010) & $\begin{array}{l}\text { clustering based on } \\
\text { high-order transient } \\
\text { harmonics } \\
\text { components }\end{array}$ & voltage & $\begin{array}{c}94 \text { appliances in } 7 \\
\text { homes }\end{array}$ & custom hardware & $1 \mathrm{MHz}$ & 6 months & $\begin{array}{c}\text { appliance } \\
\text { identification } \\
\text { rate }\end{array}$ & $94 \%$ \\
\hline
\end{tabular}


Disaggregation 45

\begin{tabular}{|c|c|c|c|c|c|c|c|c|}
\hline $\begin{array}{l}\text { Liang et al. (2010a), } \\
\text { Liang et al. (2010b) }\end{array}$ & $\begin{array}{l}\text { multiple algorithms } \\
\text { (integer } \\
\text { programming, neural } \\
\text { network, genetic } \\
\text { appliance } \\
\text { configuration space } \\
\text { exploration) and } \\
\text { decision models for } \\
\text { picking best result }\end{array}$ & $\begin{array}{l}\text { current, } \\
\text { voltage }\end{array}$ & $\begin{array}{c}27 \text { appliances (32 } \\
\text { states); } \\
\text { simulations of } \\
\text { home network } \\
\text { configurations } \\
\text { based on these } \\
\text { appliances }\end{array}$ & custom hardware & $\begin{array}{c}\text { low } \\
\text { frequency } \\
(1 \mathrm{~Hz}) \text { and } \\
\text { high } \\
\text { frequency } \\
\text { (kHz range) }\end{array}$ & not reported & $\begin{array}{c}\text { multiple } \\
\text { measures based } \\
\text { on appliance } \\
\text { identification } \\
\text { rate }\end{array}$ & $\begin{array}{c}75 \%-93 \% \\
\text { (simulated } \\
\text { configurations) }\end{array}$ \\
\hline Inagaki et al. (2011) & $\begin{array}{c}\text { appliance } \\
\text { configuration } \\
\text { distribution using } \\
\text { integer programming }\end{array}$ & $\begin{array}{l}\text { current, } \\
\text { voltage }\end{array}$ & $\begin{array}{c}42 \text { appliances of } 9 \\
\text { types }\end{array}$ & custom hardware & $40 \mathrm{kHz}$ & not reported & $\begin{array}{c}\text { appliance state } \\
\text { configuration } \\
\text { identification } \\
\text { rate }\end{array}$ & $80 \%$ \\
\hline $\begin{array}{l}\text { Kolter \& Jaakkola } \\
\qquad(2012)\end{array}$ & $\begin{array}{l}\text { machine learning of } \\
\text { temporal appliance } \\
\text { models, using } \\
\text { factorial hidden } \\
\text { Markov models }\end{array}$ & $\begin{array}{l}10 \text { principle } \\
\text { components } \\
\text { of current } \\
\text { waveform }\end{array}$ & 9 appliances & $\begin{array}{l}\text { Commercial and } \\
\text { custom hardware / } \\
10 \text { homes }\end{array}$ & $\begin{array}{c}15 \mathrm{kHz}, \\
\text { compressed } \\
\text { to } \sim 1 \\
\text { reading } / 5 \mathrm{~s}\end{array}$ & $\begin{array}{l}2 \text { weeks, non real- } \\
\text { time identification }\end{array}$ & $\begin{array}{l}\text { precision/recall } \\
\text { of total energy } \\
\text { explained }\end{array}$ & $\begin{array}{c}83 \% \text { precision, } \\
60 \% \text { recall }\end{array}$ \\
\hline
\end{tabular}




\section{Appendix B. Description of Published Algorithms}

Regarding their approach, all of the algorithms operate using what we will call the library comparison technique. Specifically, an appliance signature database or library is developed by performing physical measurements on appliances, and then new unidentified appliance signals are compared to those signatures in the library to determine the best match. Algorithm developers can create the libraries by performing their own physical measurements using plug-level monitors or acquiring such a data set from a plug monitoring company. This library comparison approach typically requires the algorithms be trained. Note that this training is performed by the algorithm developers. A second type of training involves asking consumers to correct guesses made by the system; to our knowledge this is only being utilized by a couple of commercial algorithm developers.

The problem of inferring consumer electricity use from measurements of electric circuit parameters started to gain attention in the engineering community beginning in the 1980s with studies by G. Hart and F. Schweppe at the Massachusetts Institute of Technology and the Electric Power Research Institute. Early research focused on disaggregating simple resistive appliances that have a finite number of operating states, which are typical for the residential sector (e.g., Hart, 1992; Sultanem, 1991; Marceau and Zmeureanu, 2000; Leeb et al., 1995). Some effort (e.g., Roos et al., 1994; Lee et al., 2005) has also been invested in studying electric appliances in the industrial and commercial sector, which commonly have more complicated operating principles (e.g., variable power devices such as motors).

Hart introduced the Nonintrusive Appliance Load Monitor (NALM) as a paradigm for a software system capable of analyzing single-point (e.g., home meter panel) electric data to obtain information on the energy use of individual appliances (Hart, 1992). The architecture is composed of a sensor that samples household-level power at $8 \mathrm{kHz}$ and feeds it to a device that extracts basic features and statistics on-site using $1 \mathrm{~Hz}$ averaged power, which are then transmitted to a central unit that performs appliance classification off-line. Hart's approach is based on detecting rapid changes (edges) in steady-state, fine-grain real (DP) and reactive (DQ) normalized power signals, which are used as signatures characteristic to each appliance. The 2-D space (DP, DQ) is used to pair appliance state changes for performing classification, which is done by matching appliance signatures to a databases obtained by prior intrusive calibration of each appliance. In the basic form presented in Hart (1992), the NALM method is able to disaggregate some simple appliances (minimum load $150 \mathrm{~W}$ ) that have a finite number of states (e.g., $\mathrm{ON} / \mathrm{OFF}$ ), for which Hart reports accuracies of $85 \%{ }^{35}$.

A number of studies extended the simple linear appliance model adopted by Hart (1992) to use other directly sampled quantities such as jump in current DI (e.g., Sultanem, 1991) or voltage distortion (Roos et al., 1994) to augment (and hence increase the resolving power) of the (DO, DQ) space. All these approaches require appreciable amounts (several days) of edge data to be processed off-line. They generally disregard the time taken by appliances to reach steady-state operation, and cannot disambiguate loads whose signatures overlap in the several dimensional feature space used. For example, such an approach will have a hard time distinguishing between a water heater and a toaster that draw about the same power and have similar (resistive) operational principles.

More advanced disaggregation techniques have been developed that rely on computing Fourier harmonics of steady-state current or power to further eliminate ambiguity in appliance signatures. Multiple studies attempt to extend the types of identifiable loads to lower-power, more complex devices found in modern homes and offices (e.g., computer, copier) or industrial buildings (e.g., variable speed fans) (Laughman et al., 2003; Lee, 2003; Shaw et al., 1998; Lee et

\footnotetext{
${ }^{35}$ As measure of accuracy, Hart uses the percentage of the total household energy that their approach was able to identify to the level of classes of appliances.
} 
al., 2005). In Shaw et al. (1998), current waveforms were collected at a sampling rate of several $\mathrm{kHz}$ and used to compute in-phase and quadrature spectral envelopes (time-dependent, averaged Fourier coefficients) that characterize harmonic behavior. Events are identified by performing segmentation on the envelopes rather than on the raw signal through isolating several $v$-sections (significant variations) characteristic for each type of load. In Nakano et al. (2006), the authors use fundamental and (up to 13th) odd-order current harmonics, and corresponding current-voltage phase difference as features to train an off-the-shelf Support Vector Machine (SVM) classifier to recognize the state of each appliance in a previously-calibrated database. They test their approach on 60-second resolution data collected at four households over several days both in summer and winter, and report accuracies ${ }^{36}$ ranging from $\sim 88 \%$ (for refrigerators) to $\sim 98 \%$ (for TV sets).

Another class of approaches exploits the information offered by the transient noise induced in an electrical circuit when an appliance changes operational state. Transient signal characteristics are highly dependent on the operational principle of the device and could provide more reliable, near real-time identification capability given that data is available that is sampled at high enough frequency (Laughman et al., 2003). Variations in the spectral envelopes (timevarying average Fourier coefficients) of current (Leeb et al., 1995; Shaw et al., 1998) or voltage (Laughman et al., 2003) waveforms are used to define signatures that are matched against prototypes ("exemplars") obtained for each appliance in a previous calibration phase. The match is typically performed by finding appropriate shifting and scaling parameters that minimize a least-square error criterion between events and exemplars. In Patel et al. (2007), the authors perform household-level current sampling at $1 \mathrm{MHz}$ and use transient duration and amplitude of a set of frequencies in the electric noise generated by abruptly turning on/off appliances to construct appliance signatures. They train an off-the-shelf SVM model in a preliminary calibration phase, which they use to achieve near real-time identification of $\sim 40$ appliances for 6 test homes over 6 weeks ( 3000 transient events). The reported accuracies ${ }^{37}$ range from $85 \%-$ $90 \%$ for individual, complex (varying power or inductive) loads such as hair drier or bathroom fan. Notable limitations of these approaches are that they require high-frequency sampling of electrical quantities and that electric network topology may influence the characteristics of the transients. I.e., for a different electric network (another household) that is significantly different from the test homes, a new calibration may be required. It is unlikely that any test homes would be able to emulate the characteristics of a large percentage of homes to the level of specificity that seems to be key to this type of algorithms.

Building up on Patel's work on disaggregation using high-frequency transient signatures of the house power network, Gupta et al. (2010) identify individual appliances from single-point measurements. Their system (ElectriSense) uses continuous MHz-range electromagnetic interference (EMI) waves that are characteristic to the electrical on/off switching circuits of each device type, while being consistent across home networks. They have run a 6-month experiment on seven homes, collecting over 2500 switching events for 94 individual appliances at a $1 \mathrm{MHz}$ sampling rate via custom-built hardware. A pre-processor extracts high-order harmonics from the raw measurements, which are processed through a K-Nearest-Neighbors algorithm to detect unusual events (change in appliance states). The reported accuracy (in terms of appliance identification rate) is $94 \%$.

Recent studies have explored incorporating user behavior and appliance usage information into the set of features used by a non-intrusive load monitoring system. In Ford (2009), the author proposes an Advanced Electricity Meter (AEM) that uses three sets of features (measured shortterm electric parameters, time-dependent appliance state changes, and time-of-day of usage) and a membership model that specifies the extent to which each representative features is present in

\footnotetext{
${ }^{36}$ Accuracy is there defined as the percentage of energy of several classes of appliances that was correctly identified.

${ }^{37}$ Defined as percentage of correctly identified individual loads ("hit-or-miss").
} 
each appliance. The Bayesian-inspired classification framework is trained using data collected at $\sim 12 \mathrm{kHz}$ and performs near real-time appliance identification with reported accuracies of over 95\% for a small set of appliances (including kettles, fans, hair dryers).

Other work that incorporates user behavior information has begun exploring advanced learning algorithms that operate on much coarser-sampled data (as can be currently provided by electric utilities) obtained from many real homes over extended periods of time and over a larger palette of consumer electronics. Kolter et al. (2010) use plug-level, hourly-sampled power readings over 12-24 months from approximately 600 residential homes in the Netherlands, totaling $\sim 10,000$ unique monitored devices and $\sim 50$ appliance types. They develop a structured prediction method for discriminatively training sparse coding algorithms that builds a dictionary of basis matrices corresponding to a small subset of appliance types that includes devices of similar functionality. Having access to the actual plug-level readings for all the appliances (ground truth), they are able to assess algorithm performance in a transparent manner. The metric they use for assessing disaggregation performance is proportional to the percentage of total household energy that was correctly classified (in a few classes of appliances) yielding 55\% accuracy. Note that the accuracy estimate may be inflated because whole-home consumption was derived from the sum of data from the plug-level monitors, rather than a whole-home reading which might include additional appliances.

A few authors approach the load disaggregation problem from the perspective of quickly exploring the space of possible finite-state appliance configurations that could have generated an aggregate signal, especially in the context of appliance control. For example, Baranski and Voss (2004b) generate finite-state-machine models of appliances using a genetic algorithm that combines events (steps in real power detected via a standard electricity meter) that occur a percentage of the time larger than a given threshold. They then run a clustering algorithm to assign readings obtained over one day to appliance types by their real power. Unfortunately no data characteristics or performance result is reported by the authors.

A distinct approach has been taken in Inagaki et al. (2011), whereby the single point (i.e., looking at the current and voltage waveforms at a single point in time, rather than differences in the power signal) disaggregation problem is formulated as estimating the number of appliances from each type in a discrete set via integer programming. Here, the authors divide up current readings over single waveforms to individual appliances by finding the appliance configuration that minimizes a least-square current error term. They test their method on 42 individual appliances of 9 types, sampling current and voltage data at $40 \mathrm{kHz}$ using custom-made hardware, and achieve a $80 \%$ accuracy on appliance state identification rate.

The large majority of single-point disaggregation methods make use of some notion of appliance signatures. Lam et al. (2007) advocate building a database of such signatures, and propose a method of classification of load signatures based on a voltage-current (V-I) waveform trajectory. Based on geometric shape features extracted from the V-I trajectories, they employ hierarchical clustering (based on decision trees) to assign appliance into categories. Their approach effectively groups appliances of very different purposes (e.g., CD-player and refrigerator) by their V-I shape characteristics, given they have similar operating characteristics.

Along with work on algorithmic improvement, recent studies have also explored consolidation of established techniques into commercial prototypes targeted at specific functions. In Berges et al. (2010), the authors build custom monitoring prototype using commodity hardware to collect data for one apartment, having in mind an application to personal energy auditing. They implement several existing NALM approaches, effectively experimenting with different appliance signatures proposed in the literature (real and reactive power, harmonics and transients) combined with off-the-shelf machine learning classification algorithms. In Berges et al. (2009) the same group proposes a 1-nearest neighbor algorithm on a Euclidian metric for appliance classification, which they use on real and reactive power change events, as well as harmonics detected from voltage and current data sampled at $100 \mathrm{kHz}$ from 8 different 
appliances. They report an accuracy of $79 \%$ (appliance identification rate). Using the same algorithmic approach, Berges et al. (2010) report an accuracy of 85.2\% (percentage of energy explained) for a set of 17 appliances, with data recorded over 5.5 days. In both cases, ground truth information is recorded through an initial training process in which users manually change the state of target appliances (on, off, or multistate) and record appropriate labels.

Recent research has attempted to combine the advantages of, as well as consistently compare, different disaggregation methods. In Liang et al. (2010a), the authors propose an electric-load intelligence (E-LI) platform that integrates a number of previously-proposed algorithms and approaches. The platform consists of a database of known appliance features and modules for event detection, feature extraction, and appliance clustering, which operate both on low (up to $1 \mathrm{~Hz}$ ) and high (more than $1 \mathrm{~Hz}$ ) resolution current and voltage data. The approach extracts features (as proposed in previous literature) from raw data at multiple scales (steady-state and transients) such as current waveform, real/reactive power, harmonics, instantaneous admittance waveform, instantaneous power waveform, eigenvalues (EIG), switching transient waveform (STW). The features are passed through a Committee Decision Mechanism (CDM), that obtains disaggregation results from multiple single-feature algorithms (integer programming, see Inagaki et al. (2011), genetic algorithms, see Baranski and Voss (2004b), pattern recognition using neural networks, see Sultanem (1991)) and picks the best result as picked by different mechanisms (most common occurrence, minimum residual, maximum likelihood estimation). To compare results from different algorithms, the authors introduce several consistent performance metrics based on appliance identification rate. They test their platform on a database of 27 appliances (with 32 operational modes), with data sampled at $0.128 \mathrm{~Hz}$ by comparing algorithm performance for several combinations of algorithms and features, and obtain agreements of $85 \%$ $95 \%$ in performance. In a subsequent study, Liang et al. (2010b), the same group further tests the performance of different algorithms through Monte-Carlo simulations of loads configurations. They test different algorithms they had previously incorporated into the E-LI (integer programming, genetic algorithm, neural network, least residues) and use three CDMs (named most common occurrence, least unified residue, and maximum-likelihood estimation) under many randomly-generated home appliance configurations using signatures from the aforementioned database of 27 appliances. The reported accuracies are up to $93 \%$ under metrics based on appliance identification rates. Furthermore, the authors perform a sensitivity analysis to quantify the performance of different algorithms and features combinations under varying number and types of loads that are on at the same time, and obtain worst performance for real-reactive power features under a least-residues algorithm, and best performance for the maximum likelihood estimation-based algorithm. 


\section{Appendix C. Interview Questions}

1. What are the potential applications that can be built on top of appliance-specific energy consumption information?

a. What are the benefits associated with each?

2. What are the state-of-art disaggregation techniques?

a. What does the graph of sampling frequency vs. accuracy look like?

i. What do you mean by accuracy? What appliances (make, type, etc.)?

ii. How reliable are the algorithms to noise, changing appliances, etc.

iii. Is this residential or commercial or industrial?

b. What are corresponding software requirements?

c. What are corresponding hardware requirements (CPU/memory/network)?

d. What are corresponding cost numbers?

i. In terms of implementation?

ii. In terms of wide-scale deployment?

3. What are the capabilities (sampling frequency, CPU, memory, network) of your (or known) solutions? What is planned for future?

4. What are the gaps between the ideal and existing solutions (i.e., current solutions are not up to speed with techniques identified in \#2)?

a. From a technology perspective? Why?

b. From a market perspective? Why?

c. From a policy perspective? Why?

5. What are the technology/policy recommendations?

a. What is the right mix of central/local processing?

b. What do the companies need going forward?

i. What kind of standards would speed up innovation/time-to-market?

ii. What kind of policy levers would help? 